Article

\title{
Environmental and Economic Impact of Retrofitting Techniques to Prevent Out-of-Plane Failure Modes of Unreinforced Masonry Buildings
}

\author{
Linda Giresini $^{1}\left(\mathbb{D}\right.$, Claudia Casapulla ${ }^{2, *} \mathbb{D}$ and Pietro Croce ${ }^{1}(\mathbb{D}$ \\ 1 Department of Civil and Industrial Engineering, University of Pisa, 56122 Pisa, Italy; \\ linda.giresini@unipi.it (L.G.); p.croce@ing.unipi.it (P.C.) \\ 2 Department of Structures for Engineering and Architecture, University of Napoli Federico II, \\ 80134 Napoli, Italy \\ * Correspondence: casacla@unina.it
}

Citation: Giresini, L.; Casapulla, C.; Croce, P. Environmental and Economic Impact of Retrofitting Techniques to Prevent Out-of-Plane Failure Modes of Unreinforced Masonry Buildings. Sustainability 2021, 13, 11383. https://doi.org/ $10.3390 /$ su132011383

Academic Editor: Gianluca Mazzucco

Received: 27 September 2021

Accepted: 13 October 2021

Published: 15 October 2021

Publisher's Note: MDPI stays neutral with regard to jurisdictional claims in published maps and institutional affiliations.

Copyright: (c) 2021 by the authors. Licensee MDPI, Basel, Switzerland. This article is an open access article distributed under the terms and conditions of the Creative Commons Attribution (CC BY) license (https:// creativecommons.org/licenses/by/ $4.0 /)$.

\begin{abstract}
This paper presents an innovative methodology to assess the economic and environmental impact of integrated interventions, namely solutions that improve both structural and energy performance of existing masonry buildings, preventing out-of-plane modes and increasing their energy efficiency. The procedure allows the assessment of the environmental and the economic normalized costs of each integrated intervention, considering seismic and energy-saving indicators. In addition, the work introduces in relative or absolute terms two original indicators, associated with seismic displacement and thermal transmittance. The iso-cost curves so derived are thus a powerful tool to compare alternative solutions, aiming to identify the most advantageous one. In fact, iso-cost curves can be used with a twofold objective: to determine the optimal integrated intervention associated with a given economic/environmental impact, or, as an alternative, to derive the pairs of seismic and energy performance indicators associated with a given budget. The analysis of a somehow relevant case study reveals that small energy savings could imply excessive environmental impacts, disproportionally increasing the carbon footprint characterizing each intervention. Iso-cost curves in terms of absolute indicators are more suitable for assessing the effects of varying acceleration demands on a given building, while iso-cost curves in terms of relative indicators are more readable to consider a plurality of cases, located in different sites. The promising results confirm the effectiveness of the proposed method, stimulating further studies.
\end{abstract}

Keywords: $\mathrm{CO}_{2}$ emissions; carbon footprint; sustainable buildings; climate change; out-of-plane mechanisms; economic impact; environmental impact; CFRP; tie-rods; kinematic analysis

\section{Introduction}

Buildings and constructions are extremely impactful in terms of global energy consumption and greenhouse gases emissions, enhancing global warming. For this reason, mitigation policies seek low-impact solutions not only for new structures, but also for refurbishment and retrofitting of existing buildings. In the general framework of the life cycle cost analysis, the definition of more efficient refurbishment and retrofitting techniques requires a multi-disciplinary approach, based on a smart iterative procedure, where solutions addressing various issues are suitably combined, taking into account, besides structural and building engineering aspects, acoustic and energetic engineering needs. So far, since involving intricate multi-disciplinary problems, viable and general enough solutions of this type have been rarely investigated, researchers' attention being mainly devoted to specific issues. For this reason, professional engineers are usually unaware of ad hoc combined methodologies aiming to reduce the environmental and economic impacts of refurbishment interventions on existing buildings, also because a specific standardization is still lacking. The introduction of powerful and easy-to-use tools is thus a 
prerequisite to spread these applications into the common engineering practice, optimizing their effectiveness. Some recent works analyzed the reduction of the carbon footprint in existing industrial infrastructures [1] and the environmental impact of flooring systems [2] and of public buildings [3], the latter also considering life cycle assessment.

In principle, individual solutions cover, with an increasing degree of extension, three different levels: the material level, the element level, and the building level, while combined interdisciplinary solutions typically apply to the element level and to the building level.

Concerning the material level, multiple solutions may be selected depending on the building material. For instance, hemp-based materials were recently proposed [4]; dealing with concrete, solutions based on geopolymer [5], plants [6], and recycled aggregates [7] are increasingly popular. Dealing with unreinforced masonry, solutions implementing hemp fibers and other bio-natural materials are often used [8,9], while innovative applications of composite materials can be envisaged for exposed masonry, especially in heritage constructions [10]. However, it should be noticed that these materials, although ecological in principle, may have some disadvantages (shrinkage and durability) and a pollutant potential (e.g., for concrete with recycled plastic fibers [11]).

Evidently, as already remarked, when one shifts to the element level, or to the building level, the assessment of appropriate retrofitting techniques requires duly considering, besides the enhancement of mechanical and thermal performances, also the improvement of acoustic performances, when necessary. The interaction between these multiple points of view generates an "integrated" intervention, aiming to find the optimum, i.e., the best possible compromise among often opposite requirements. Recently, a methodology to assess the beneficial effect of retrofitting solutions was proposed for masonry walls without openings [12], arriving at a proposal for integrated interventions involving both the seismic response and the thermal behavior. Economic and environmental iso-cost curves were suggested to define the impact of each integrated intervention. The methodology was then updated in [13] to consider openings with equivalent transmittance parameters. In a further stage of research, iso-performance curves were proposed as a decisional tool also including life cycle cost analysis (LCCA) and life cycle assessment (LCA) [14]. Analogous design procedures were recently proposed in [15] for reinforced concrete existing buildings. Moreover, it must be remarked that, on the one hand, LCCA analysis involves aspects, such as the maintenance policy, that are outside the direct designer control [16]; on the other hand, climate change can also directly impact the structural reliability, modifying the climatic actions [17-19].

A further evolution of this methodology is represented by the prevention of out-ofplane (OOP) failure modes in existing masonry buildings, or more generally in heritage structure [20], for which guidelines to assess the impact of seismic retrofitting techniques could be extremely helpful in view of practical applications. The seismic assessment and retrofitting of existing masonry buildings are particularly intricate, since they depend on the floor slab features. If the floor slabs are both stiff enough in their own plane and effectively connected to the walls, the seismic performance of the building is governed by its global behavior [21,22]; if not, it is controlled by local failure mechanisms. The local mechanisms can be studied by means of linear and non-linear kinematic approaches [23-26] or making use of refined transient non-linear analyses [26-28], aiming to exclude out-of-plane failures [29]. This issue is particularly relevant for historic structures, where the connections between horizontal diaphragms and walls are poor [30]. The most common retrofitting strategies for limiting the risk of OOP failure modes are steel tie-rods [24,31], CFRP, GFRP, and strength anchors [32,33] but also new generation dissipative devices [34,35] recently proposed to prevent and control OOP damage. Obviously, global analyses are admissible only as long as premature failures due to local mechanisms are excluded [36].

The present paper proposes and applies an original methodology to assess the impact of integrated retrofitting techniques for the mitigation of the local seismic vulnerability of existing masonry buildings, where OOP mechanisms are predominant. 
More in detail, Section 2 presents the general methodology to assess the economic and the environmental impact of integrated retrofit techniques, contrasting OOP mechanisms of existing masonry buildings, detailing seismic and energy performance indicators. Then, the methodology is applied to a case study presented in Section 3, illustrating the operational approach, and its consequences, both in terms of strengthening and thermal insulation objectives.

The novelty of the proposed method is the introduction of a unified multidisciplinary approach for retrofitting existing masonry buildings, which suitably combines strengthening interventions with energy saving interventions. The main goal is to assess the economic and environmental impact of integrated interventions in view of the implementation of appropriate strategies for a more sustainable allocation of the available resources. Although the present study focuses, from the structural point of view, on interventions aiming to prevent the out-of-plane modes and, from the energy saving point of view, on the application of insulating panels (IPs), the proposed approach is much more general, being easily extendable to other kinds of intervention.

It must be remarked that the objective of the paper is to discuss the proposed procedure and to illustrate how various types of interventions can be compared by means of an appropriate sensitivity analysis and not to establish a cost hierarchy among the interventions. In fact, the direct costs of the intervention can be sensibly variable not only over time, as a function of the demand and offer ratio, but also depending on the country, the local market conditions, the availability and the sustainability of the material, the carbon footprint associated to the production and transport of one cost unit of the product, the evolution of monetary and fiscal policy aiming to promote or prevent use of specific products, and so on.

A sound way to notionally define direct costs of an integrated intervention is the embodied energy (EE): "EE can be defined as the energy consumed during a building whole life cycle; this excludes the operating energy, but includes raw material extraction, product production, manufacturing, installation, on-site construction, maintenance, repair and replacement, and finally the demolition and disposal of a building" [37-39]. Embodied carbon (EC) is an analogous concept. In [40], solutions to maximize both energy efficiency and environmental efficiency are illustrated, pondering the design alternatives in both the operational and embodied phases. Hsien Wei et al. [41] analyze the sustainability performance of a single RC building under seismic risk and a methodology to translate seismic building damage in a quantifiable social, environmental, and economic impact.

However, although EE and EC are commonly used when performing a LCCA, it must be recalled again that some addends of EE and EC, for example, use, maintenance, repair, replacement, demolition, and disposal, are outside the designer's control. In addition, the evaluation of indirect costs is a very difficult task since it involves aspects, and political choices, that the designer, and even the owner of the building, cannot govern.

\section{Methodology}

2.1. Analysis Steps

Referring to the assessment of the seismic vulnerability of an unreinforced masonry building, the environmental and economic impacts of retrofitting techniques to prevent OOP failure modes can be evaluated according to the following steps (Figure 1):

1. Identification of the most likely OOP mechanism through the kinematic approach of limit analysis [29].

2. Proposal of integrated solutions based on feasibility rules and on available materials nearby the construction site, duly considering the impact related to the transport phase.

3. Linear/non-linear static and/or non-linear transient analysis in the actual and in the retrofitted configuration, for each integrated solution.

4. Calculation of seismic and energy performance indicators to quantify the beneficial effects of each integrated solution. 
5. Plot of iso-cost capacity and demand curves and/or of iso-performance curves to identify the optimal strategy for decision-makers.

6. Iteration of steps 4-5 to include a simplified life cycle assessment and/or life cycle cost analysis of each integrated intervention.

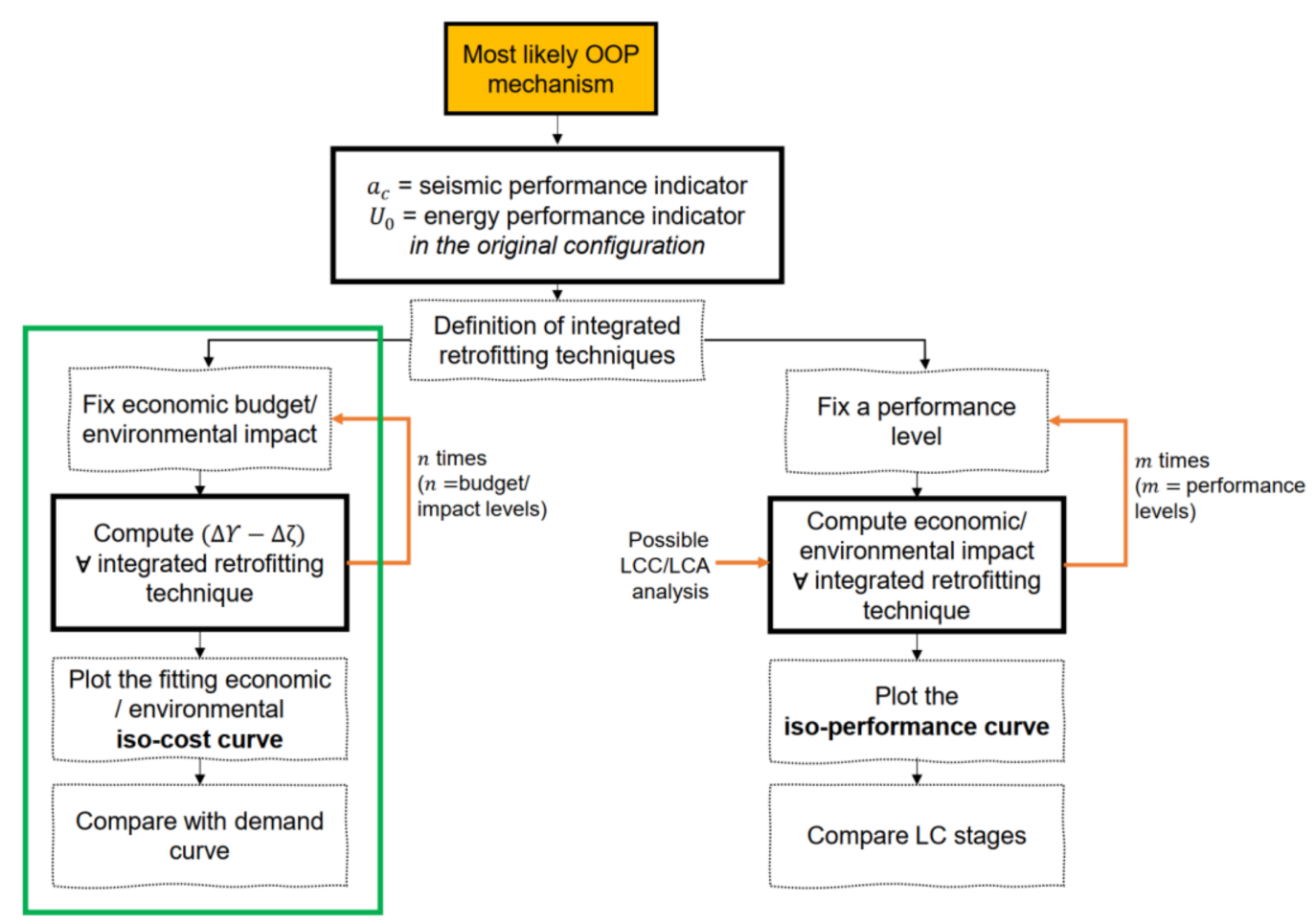

Figure 1. Schematics of the proposed procedure for the selection of optimal integrated retrofitting techniques for OOP failure modes in masonry buildings. Only the part framed in green is developed in this paper.

The entire process is then repeated for each OOP mechanism potentially affecting the considered masonry building. Afterwards, the global seismic analysis of the whole building can be performed by following traditional or more innovative procedures [42].

In this paper, an emblematic OOP failure mode of masonry building is considered, and the steps from (2) to (5) are performed to obtain the iso-cost curves (within the green frame in Figure 1). The application of life cycle assessment and of the methodology to obtain iso-performance curves will be presented in future works.

\subsection{Definition of Integrated Interventions}

Integrated interventions capable of counteracting the OOP mechanisms of masonry buildings can be numerous. Among typical strengthening measures, one can cite tierods [24,31], a traditional retrofitting measure for preventing OOP failure modes, CFRP and GFRP strips [43] vertically placed GFRP nets, ferro-cement, strength anchors [32,33], trusslike steel strips reinforcement [44], or rolls of fiber fabrics inserted in the masonry courses by using indent technique [5]. However, when the objective of the intervention is not only to improve the structural performance but also the thermal behavior of the building, these interventions are often associated with the implementation of energy-saving measures, such as the application of insulating panels. Moreover, since some strengthening techniques, such as CFRP/GFRP strips/nets, ferro-cement, or truss-like steel strips reinforcement, require the removal of the old plaster layer and new plastering, during the execution of this kind of intervention, the thermal transmittance of the walls can be further decreased by using less conductive plastering materials.

To derive the economic and environmental iso-cost curves, the starting point is the computation of the unit costs for each integrated intervention. To better compare the 
different retrofitting techniques, reference to the unit economic and environmental costs as costs per square meter seems a particularly convincing approach. These costs can be derived from regional/national lists and databases, duly considering the environmental impacts and quantifying the global warming potential in terms of carbon footprint. The carbon footprint is expressed in terms of $\mathrm{CO}_{2}$ emissions for product unit, and its value can be obtained from commercial software packages or national databases. It is worth noticing that databases included in a software package and price lists can often differ from each other, also in function of the extension of the intervention: this is a delicate aspect, since the economic/environmental impacts can be strongly influenced by these preliminary assumptions. It is therefore recommended to select databases that are sound and appropriate for the case study under consideration. Since, in some circumstances, there are peculiar site conditions, such as unusual distance from industrial areas, or other transportation difficulties, that can raise the transport quotas, both in terms of costs and carbon dioxide emissions, the database, or the economic and environmental impact analysis, which should be suitably adapted to reflect the specific features of the considered construction site.

Market research is strongly encouraged, also focusing on local enterprises, with the twofold objective of selecting sound values and optimizing the transportation costs to the construction site.

Once the unit costs are derived, the effectiveness of an integrated intervention can be assessed introducing appropriate performance indicators, each one associated with a specific aspect of the integration. These performance indicators should combine ease of use and representativeness, being at the same time as independent as possible of the operator. For the purposes of the present study, two particularly significant indicators have been identified: the seismic performance indicator, measuring the effectiveness of the intervention from the structural point of view, and the energy performance indicator, measuring the effectiveness of the intervention from the thermal insulation point of view.

A very impressive and synthetic way to compare different integrated solutions is plotting iso-cost and iso-performance curves in the plane $\Delta a_{c}-\Delta U, \Delta a_{c}$ and $\Delta U$ being the seismic performance indicator and the energy perfomance indicator, respectively, better described in the following. Evidently, depending on the specific investigated feature, iso-cost and iso-performance curves can be drawn referring to either economic or environmental aspects.

\subsection{Seismic Performance Indicator}

The seismic performance indicator, quantifying the improvement of seismic performance gained through the retrofitting technique, can be defined in terms of acceleration capacity, before and after the integrated intervention. Considering a rigid block chain simulating the OOP mechanism and a force-based approach, the meaningful parameter is $a_{c}$, which is defined in [45] as the acceleration capacity of an equivalent single degree of freedom oscillator. It is herein assumed that $a_{c, 0}$ refers to this parameter in the original configuration of the mechanism (before retrofitting), whilst $a_{c, 1}$ indicates the acceleration capacity in its retrofitted condition. A first seismic performance indicator is the ratio between the acceleration capacity increase resulting from the retrofitting and the original capacity, as expressed by:

$$
\Delta a_{c}=\frac{a_{c, 1}-a_{c, 0}}{a_{c, 0}} .
$$

This indicator is valid in a relative sense with respect to the original capacity, but it does not provide information in an absolute sense. It is crystal clear that the significance of a given value of $\Delta a_{c}$ strongly depends on the initial capacity $a_{c, 0}$ : for example, the benefit of having $\Delta a_{c}=0.3$ can be nearly insignificant, both if $a_{c, 0}$ is low, and, vice versa, if $a_{c, 0}$ is high (too safe-sided). In other words, the first seismic performance indicator solely gives a partial information about the structural enhancement attained through the intervention. 
A second seismic performance indicator is an absolute parameter that reads:

$$
\Delta \zeta=\frac{\zeta_{1}-\zeta_{0}}{1-\zeta_{0}}
$$

where $\zeta=\frac{a_{c}}{a_{d}}$ is the ratio between the capacity, $a_{c}$, and the demand, $a_{d}$, in terms of acceleration [46]. The sub-index 0 refers to the original condition (without retrofitting), whilst the sub-index 1 indicates the retrofitted configuration, after the intervention. Such an indicator equals 0 when the intervention does not provide any enhancement $\left(\zeta_{1}=\zeta_{0}\right)$ and equals 1 when the capacity gained with the intervention is equivalent to the demand, in other words, when the intervention allows gaining what is lacking to fully satisfy the demand.

The acceleration capacity $a_{c}$ can be calculated by performing a kinematic analysis, based on either the Heyman's model [47] or the frictional model [24,25,29]. Of course, the acceleration demand $a_{d}$ can be derived for the selected construction site by National Standards, such as [46], or by suitable refined studies.

\subsection{Energy Performance Indicator}

The first energy performance indicator, $\Delta U$, quantifying the improvement of the energetic performance gained from the energy saving intervention, can be defined in terms of average thermal transmittance, before and after the integrated intervention. Analogously to what was proposed for the seismic performance indicator, in the present case, $U_{0}$ designates the thermal transmittance in the original configuration of the mechanism (before retrofitting), whilst $U_{1}$ refers to its retrofitted condition. The ratio between the thermal transmittance decrease resulting from the intervention and the original transmittance is thus:

$$
\Delta U=-\frac{U_{1}-U_{0}}{U_{0}} .
$$

The thermal transmittance can be computed referring to the relevant international standards, such as EN ISO 6946:2017 [48] for thermal resistance values and EN ISO 10077:2017 [49] for thermal transmittance of glass panels. Indeed, when openings are present, the thermal transmittance of glass panels should be considered, as explained in $[13,14]$. The thermal transmittance of walls with openings can be synthetically represented by a unique averaged unit value, $U$, which takes into account all the relevant parameters: the thermal transmittances of the wall, $A_{m} \cdot U_{m}$, the thermal transmittance of the windows, $A_{w} \cdot U_{w}$, and the heat flux through the thermal bridges, $l \cdot \Psi$. The unit thermal transmittance $U$ is, obviously, expressed by:

$$
U=\frac{A_{m} \cdot U_{m}+A_{w} \cdot U_{w}+l \cdot \Psi}{A_{m}+A_{w}},
$$

where:

- $A_{m}$ is the net area of the wall involved in the mechanism;

- $U_{m}$ is the unit thermal transmittance of the wall;

- $A_{w}$ is the total area of the windows;

- $U_{w}$ is the windows unit thermal transmittance;

- $\quad l$ is the total length of the thermal bridge, and

- $\Psi$ is the unit thermal transmittance of the thermal bridge, as provided by EN ISO 10211:2017 [50].

As discussed for the seismic performance indicator, $\Delta U$ only gives partial (relative) information about the enhancement attained with the retrofitting solution. Therefore, a 
second (absolute) energy performance indicator is introduced analogously to what has been done for the seismic performance indicator (see for details Section 2.3):

$$
\Delta \mathrm{Y}=\frac{\mathrm{Y}_{1}-\mathrm{Y}_{0}}{1-\mathrm{Y}_{0}},
$$

where $\mathrm{Y}=U_{c} / U_{d}$ is the ratio between the capacity, $U_{c}$, and the demand $U_{d}$ in terms of thermal transmittance. The sub-index 0 refers to the as-built condition (without retrofitting), whilst the sub-index 1 indicates the retrofitted configuration, after the intervention. Analogously to the seismic performance indicator $\Delta \zeta, \Delta Y$ equals 0 when the intervention does not provide any enhancement $\left(Y_{1}=Y_{0}\right)$ and equals 1 when the capacity gained with the intervention equals the demand.

Whilst the thermal transmittance $U_{c}$ can be calculated with Equation (4) following the procedures indicated by the above-mentioned ENI ISO standards, the demand $U_{d}$, usually provided in National Standards, such as [37], depends on the climatic zone of the construction site, which can be identified, for example, by assigning the pertinent number of Degree Day.

\subsection{Economic and Environmental Iso-Cost Curves}

Starting from a given either economic budget or environmental impact, the corresponding seismic and energy performance indicators can be evaluated for each integrated intervention. The given economic budget and environmental impact are normalized to unit area; therefore, the economic budget is expressed in Euros $/ \mathrm{m}^{2}$ and the environmental impact is quantified in $\mathrm{kgCO} 2 \mathrm{eq} / \mathrm{m}^{2}$ (emissions of equivalent carbon dioxide). The point of coordinates $\left(\Delta U, \Delta a_{c}\right)$, or $(\Delta Y, \Delta \zeta)$, which expresses the combined indicator, is included in the graph plotting the relationship between the two indicators $\Delta U$ and $\Delta a_{\mathcal{C}}$ (or between the two absolute indicators $\Delta \mathrm{Y}$ and $\Delta \zeta$ ).

For each considered integrated solution, the procedure is repeated $n$ times, $n$ being the number of the investigated levels, in terms of economic budget or environmental impact. Consequently, $i$ is the number of the integrated solutions considered in the analysis, and each graph counts $i \times n$ combined indicators, scattered at intervals.

For each economic budget and for each environmental impact, suitably fitting contours can be then found from the scattered indicators, thus obtaining a parameteric representation of the economic budget, or of the environmental impact. The fitting curves are thus economic iso-cost curves, if the variation of economic budget is considered, or environmental iso-cost curves, if the variation of environmental impact is accounted for.

\subsection{Life Cycle Cost Analysis of the Integrated Interventions}

Regarding the life cycle assessment of the assumed integrated retrofit technique, a preliminary step consists in identifying the appropriate system boundaries to be considered. According to UNI-EN 15804:2012 [51], the relevant boundaries generally used when performing a LCCA are: cradle to gate, cradle to site, cradle to handover, cradle to end of use, cradle to grave, and cradle to cradle, but in the definition of embodied energy (EE), common references are cradle to gate and cradle to handover boundaries [39]. Definitions for embodied carbon (EC) were found considering cradle to gate and cradle to handover. More detailed literature about EE and EC can be found in [39].

However, taking into consideration that, as already remarked, LCCA involves aspects pertaining to the whole life of the construction, from birth to death, which are outside the designer's control, the proposed approach should be intended as a part, although fundamental, of a more complex procedure involving other "actors", in particular the owners, and, above all else, the policy makers. As the outcomes of LCCA are often heavily influenced by subjective choices about the most appropriate use and management strategies of the construction, this aspect is not further considered here. 


\section{Case Study: Description and Performance Indicators}

The proposed procedure has been applied to a relevant case study selected as a real and general example: a four-story masonry building (Figure 2a), located in Southern Italy. All the data for geometry, material properties and site parameters were provided by the University of Catania [52].

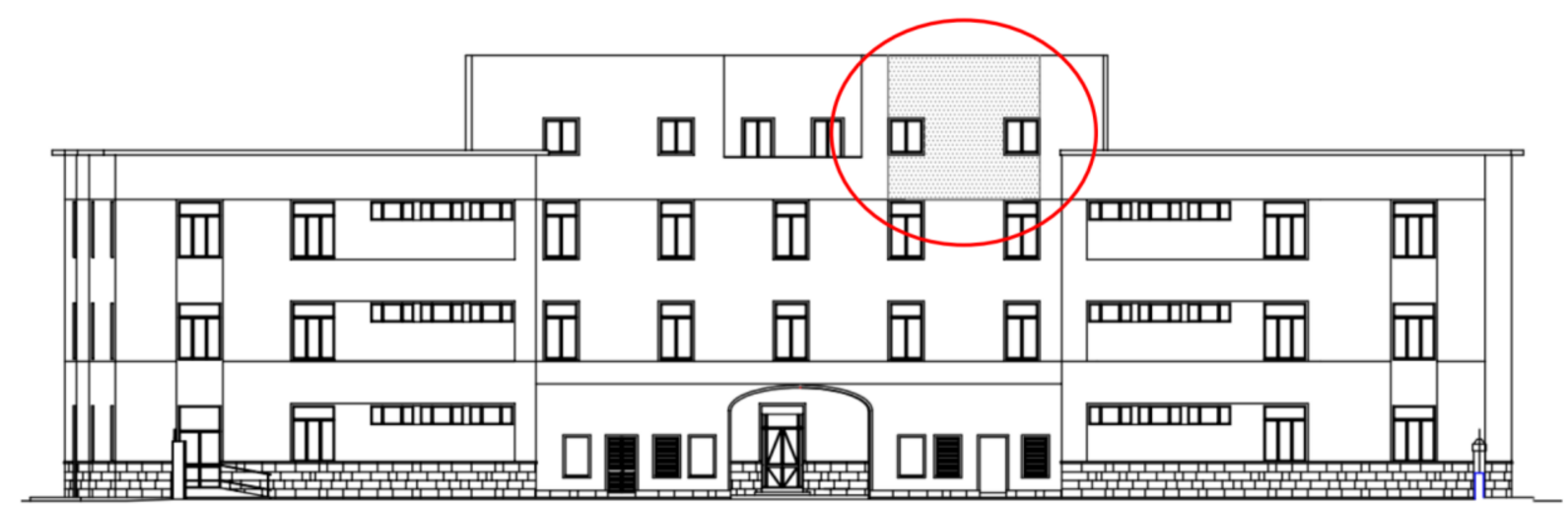

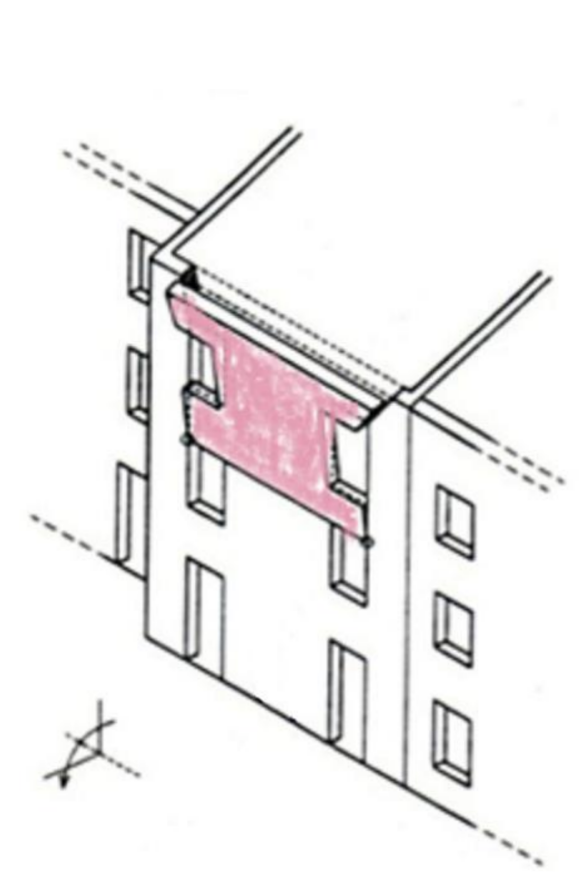

(b) (a)

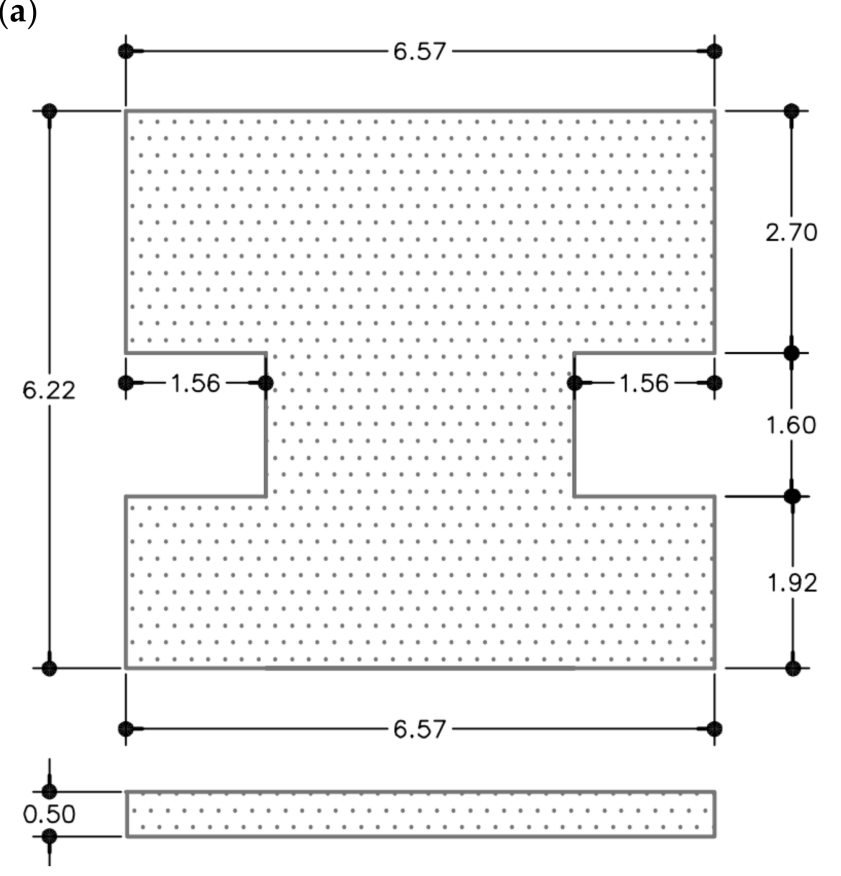

(c)

Figure 2. (a) Rear façade of the case study building; (b) schematic type of the mechanism under study; (c) geometric dimensions $(\mathrm{m})$ of the considered rocking wall.

\subsection{Description of the Case Study and Failure Mechanism}

The failure mechanism chosen for the application of the proposed procedure is an OOP mode that could be activated in the considered building at the top story. It is a simple outward overturning mode, characterized by the formation of a typical horizontal hinge at the wall base, due to weak or unproper structural connections with the roof. The wall participating in the mechanism, schematically illustrated in Figure $2 b$, is represented by the masonry portion surrounding the two openings. The gross area of the wall, including openings, is $40.87 \mathrm{~m}^{2}$, while the net masonry area is $35.87 \mathrm{~m}^{2}$ (Figure 2c).

The floors of the building are horizontal reinforced concrete diaphragms; the wall thickness at the fourth story is $0.5 \mathrm{~m}$. Evidently, the knowledge of the mechanical properties of masonry is not strictly needed to perform a linear kinematic analysis; in fact, limit 
analysis only involves the geometrical characteristics of the rigid-like block shown in Figure 2c. However, to compute the acceleration capacity attained with CFRP strips according to the formulations indicated in [53], the knowledge of the mean values of the compressive and tensile strength of the stone units is required. For the irregular limestone masonry wall under study, we hypothesize a mean compressive strength $f_{b m}=18 \mathrm{MPa}$, and a tensile strength $f_{b t m}=10 \% f_{b m}=1.8 \mathrm{MPa}$. Note that the used notations comply with CNR-DT 200 R1/2013 [41], where $f_{b m}$ corresponds to $f_{b}$ in the European standards.

\subsection{Integrated Interventions and Unit Costs}

The selected integrated interventions for limiting the seismic vulnerability and improving the energy performance considered in the case study are:

(a) insulating panels alone (IP);

(b) steel tie-rods with constant diameter plus insulating panels (tie-rods $\mathrm{d}_{\text {const }}+\mathrm{IP}$ );

(c) steel tie-rods with variable diameter plus insulating panels (tie-rods $\mathrm{d}_{\mathrm{variable}}+\mathrm{IP}$ );

(d) carbon fiber reinforced polymer strips plus insulating panels (CFRP + IP).

To substantiate the comparison, the installation of IP has been considered in turn as a separate intervention, or, in combination with either tie-rods or CFRP strips, as part of an integrated solution.

For the sake of this example, the economic unit costs have been derived from Italian price lists [54], while the unit quantities of $\mathrm{CO}_{2}$ emissions for different materials, except CFRP, have been extracted from a commercial software database [55]. The $\mathrm{CO}_{2}$ emissions per kg of CFRP material have been derived from [56].

The costs are summarized in Table 1, where the cost of the plaster removal is reported in a separate column, since this operation is quite mandatory when the strengthening intervention includes application of tie-rods or CFRP strips. The unit economic costs are expressed per square meter of panel/strips/plaster surface (for IP/CFRP/plaster), and per square meter of retrofitted masonry façade (for tie-rods).

Table 1. Unit costs for the selected integrated interventions (IP = insulating panel).

\begin{tabular}{ccccc}
\hline Cost & IP $\boldsymbol{t}_{\boldsymbol{I P}}=\mathbf{1 0 0} \mathbf{~ \mathbf { m }}$ & No. 2 Tie-Rods $\boldsymbol{d}=\mathbf{2 2} \mathbf{~ m m}$ & CFRP & Plaster Removal \\
\hline Economic $\left(€ / \mathrm{m}^{2}\right)$ & 190 & $12^{1}$ & 350 & 10.0 \\
Environmental $\left(\mathrm{kgCO}{ }_{2} \mathrm{eq} / \mathrm{m}^{2}\right)$ & 34 & $22^{1}$ & $18.4^{2}$ & 3.4 \\
\hline & ${ }^{1}$ per square meter of the entire wall (area $\left.=40.86 \mathrm{~m}^{2}\right){ }^{2}$ per $\mathrm{kg}$ of CFRP.
\end{tabular}

In the reference case, considering that the gross area is about $41 \mathrm{~m}^{2}$, the most appropriate tie-rod strengthening intervention consists in the application of two steel bars, $22 \mathrm{~mm}$ in diameter and $5 \mathrm{~m}$ long, so guaranteeing a demand over capacity ratio greater than $1.0(\Delta \zeta=1.06$, see Section 3.3). Additionally, four uniaxial CFRP strips, $200 \mathrm{~mm}$ wide and $1.5 \mathrm{~m}$ long, with ultimate tensile resistance of about $50 \mathrm{kN}$ are considered for the alternative strengthening intervention, providing $\Delta \zeta=1.11$, as described in Section 3.3.

The unit economic cost of the steel intervention on the masonry façade (Figure $2 b$ ) has been obtained by dividing the available total budget, which is 480 euros, including both material and labor costs, [54], by the area of the gross area of the façade itself. Instead, CFRP strips and plaster removal are assumed to have unit economic costs of $350 € / \mathrm{m}^{2}$ and $10 € / \mathrm{m}^{2}$ [54], respectively. As the unit economic costs of IP/CFRP and tie-rods reported in Table 1 cannot be directly compared, in the calculation of iso-cost curves, they have been uniformed and expressed in terms of unit area of masonry wall to retrofit.

The environmental cost of tie-rods is again normalized in terms of gross unit area of masonry wall. To compute it, a total value of $10.8 \mathrm{kgCO}_{2}$ eq has been considered for the above-mentioned reference steel tie rod $(d=22 \mathrm{~mm})$, whose total mass is $14.9 \mathrm{~kg}$. It must be underlined that the emission rate of $0.41 \mathrm{kgCO}_{2}$ eq per $10 \mathrm{~kg}$ of steel, associated with waste transportation and process, has been disregarded in the analysis, being part of other 
life cycle phases (usage and final disposal). These are, in fact, outside the horizon of the present exercise, which concerns only the installation of the retrofitting solutions.

The economic and environmental costs for insulating panels are valid for polystyrene slabs of density $20 \mathrm{~kg} / \mathrm{m}^{3}$. Referring to a $100 \mathrm{~mm}$ thick polystyrene panel, a flat rate cost of $190 € / \mathrm{m}^{2}$ and an emission rate of $34 \mathrm{kgCO}_{2} \mathrm{eq} / \mathrm{m}^{2}$ have been considered for them. CFRP strips and plaster removal are assumed to have environmental costs of $18.4 \mathrm{kgCO}_{2} \mathrm{eq} / \mathrm{kg}_{\mathrm{CFRP}}$ and $3.4 \mathrm{kgCO} \mathrm{eq}_{2} / \mathrm{m}^{2}$, respectively.

\subsection{Seismic Analysis and Seismic Performance Indicators}

The seismic assessment of OOP failure mechanisms in unreinforced masonry buildings can be carried out using force-based and displacement-based methods [45]. Keeping the purpose of this paper mainly addressed to the integrated approach, the former is preferred herein and the ultimate limit state (ULS) or life-safety is considered for the original and retrofitted configurations of the wall under study. The macro-block modeling approach of Casapulla et al. $[24,29]$ is adopted to also take into account the contribution of frictional resistances.

Using the linear kinematic approach of limit analysis, the force-based method predicts the spectral acceleration as a function of the force capacity of the wall, corresponding to the collapse of the out-of-plane loaded wall. This acceleration capacity is [45]:

$$
a_{\mathcal{C}}=\frac{\alpha_{0} g}{e^{*} C F},
$$

where $\alpha_{0}$ is the ultimate load multiplier, $g$ the gravitational acceleration, $e^{*}$ the rate of the total mass participating in the rocking mechanism, and $C F$ a confidence factor, which takes into account the available level of knowledge of structural properties. Since $C F$ is not an objective property of the structure but some kind of additional safety factor, in the following, we assume $C F=1$.

If the mechanism occurs at a height $Z$ above the level of application of the seismic action, as in the case study, the seismic input amplification due to the filtering effect of the main building should be evaluated, at least for the first vibration mode; in fact, the contribution of higher modes is negligible for simple rocking. According to [45], the spectral acceleration demand takes into account the fundamental period of the building $T_{1}$ in the considered direction and the behavior factor $q$, through the formulation:

$$
a_{d}=\frac{\gamma_{1}\left|\psi_{1}(Z)\right| S_{e}\left(T_{1}, \xi_{1}\right) \sqrt{1+0.0004 \xi_{1}^{2}}}{q},
$$

where $S_{e}\left(T_{1}, \xi_{1}\right)$ is the expected spectral acceleration of the elastic response spectrum, depending on the fundamental period $T_{1}$, and on the equivalent viscous damping $\xi_{1}(\%)$, while $\psi_{1}(Z)=Z / H$ is the first vibration mode displacement in the considered direction at the height $Z$, normalized to that at the building top. The corresponding modal participation coefficient, $\gamma_{1}$, can be evaluated as a function of the total number of floors, $N$, as $\gamma_{1}=3 N /(2 N+1)$.

Finally, the seismic check is satisfied if the following relationship is fulfilled:

$$
a_{c} \geq a_{d}
$$

considering that the spectral acceleration demand $a_{d}$ depends on both the probability of exceedance $P_{N C R}$ referred to the no-collapse requirement (ULS) and the notional reference life.

To calculate the spectral acceleration demand and capacity with reference to the case study wall in the original and retrofitted configurations, it is first necessary to assign all the involved parameters. Starting from the seismic action to be considered for ULS assessments, the spectral parameters characterizing the site are summarized in Table 2, 
including the control periods of the response spectrum, namely $T_{B}, T_{C}$, and $T_{D}$ and the value of the acceleration demand derived from Equation (7). As $T_{B}<T_{1}<T_{C}$, it is worth noting that $S_{e}\left(T_{1}, \xi_{1}\right)$ lies in the plateau range of the response spectrum; it is given by:

$$
S_{e}\left(T_{1}, \xi_{1}\right)=a_{g} S \eta F_{0}
$$

where $a_{g}$ is the design ground acceleration on type A ground, $S$ the soil factor, $F_{0}$ the spectral amplification factor, and $\eta$ the factor accounting for the viscous damping: $\eta=\max \left(0.55 ; \sqrt{10 /\left(5+\xi_{1}\right)}\right)\left(\eta=1\right.$ if $\left.\xi_{1}=5 \%\right)$. According to [45], the behavior factor $q$ in Equation (7) has been taken as equal to 2 .

Table 2. Seismic parameters at ULS [46].

\begin{tabular}{cccccc}
\hline \multicolumn{6}{c}{ Site Parameters (ULS) } \\
\hline$a_{g} / g$ & $F_{0}$ & $S$ & $T_{B}(\mathbf{s})$ & $T_{C}(\mathbf{s})$ & $T_{D}(\mathbf{s})$ \\
\hline 0.2 & 2.36 & 1.42 & 0.2 & 0.6 & 2.4 \\
\hline \multicolumn{7}{c}{ Spectral Parameters (ULS) } \\
\hline$\xi_{1}(\%)$ & $\gamma_{1}$ & $\psi_{1}(Z)$ & $T_{1}(\mathbf{s})$ & $\begin{array}{c}S_{e}\left(T_{1}, \xi_{1}\right)\left(\mathbf{m} / \mathbf{s}^{2}\right) \\
\text { (Equation (9)) }\end{array}$ & $\begin{array}{c}a_{d}\left(\mathbf{m} / \mathbf{s}^{2}\right) \\
\text { (Equation (7)) }\end{array}$ \\
\hline 5 & 1.33 & 0.68 & 0.458 & 6.58 & 2.98
\end{tabular}

The calculation of the spectral acceleration capacities has been carried out considering the schemes summarized in Figure 3, where the vertical sections of the unreinforced wall (URW) (Figure 3a) of the wall retrofitted with tie-rods (RWT) (Figure 3b) and of the wall reinforced with CFRP strips (RWS) (Figure 3c) are sketched. As introduced above, the reference tie-rod is a steel bar, $5 \mathrm{~m}$ long, having a diameter $d=22 \mathrm{~mm}$, while the reference CFRP strip is a uniaxial fabric, $200 \mathrm{~mm}$ wide and $1.5 \mathrm{~m}$ long, whose ultimate tensile resistance is about $50 \mathrm{kN}$. The most relevant materials properties and dimensions used in the analysis are summarized in Table 3.

Table 3. Materials properties and dimensions for the wall and the reinforcements.

\begin{tabular}{|c|c|c|c|c|c|}
\hline \multicolumn{6}{|c|}{ Masonry Wall } \\
\hline$\gamma\left(\mathbf{k N} / \mathrm{m}^{3}\right)$ & $t(\mathrm{~m})$ & $h_{b}(\mathrm{~m})$ & $l_{b}(\mathrm{~m})$ & $n_{b}$ & $f$ \\
\hline 19 & 0.5 & 0.2 & 0.2 & 13 & 0.6 \\
\hline \multicolumn{6}{|c|}{ Steel Tie-Rods } \\
\hline$f_{y, d}(\mathbf{M P a})$ & $A_{s}\left(\mathrm{~mm}^{2}\right)$ & & & & \\
\hline 205 & 254.47 & & & & \\
\hline \multicolumn{6}{|c|}{ CFRP Strips (Uniaxial $300 \mathrm{~g} / \mathrm{m}^{2}$ ) } \\
\hline$b_{f}(\mathrm{~mm})$ & $t_{f}(\mathrm{~mm})$ & $E_{f}(\mathrm{MPa})[57] *$ & $f_{b m}(\mathrm{MPa})$ & $f_{b t m}(\mathrm{MPa})$ & $k_{b} \cdot k_{G}$ \\
\hline 200 & 0.17 & 83848 & 18 & 1.8 & 0.015 \\
\hline
\end{tabular}

${ }^{*}$ The specific modulus here considered is valid for a percentage of carbon fiber by about $30 \%$. 

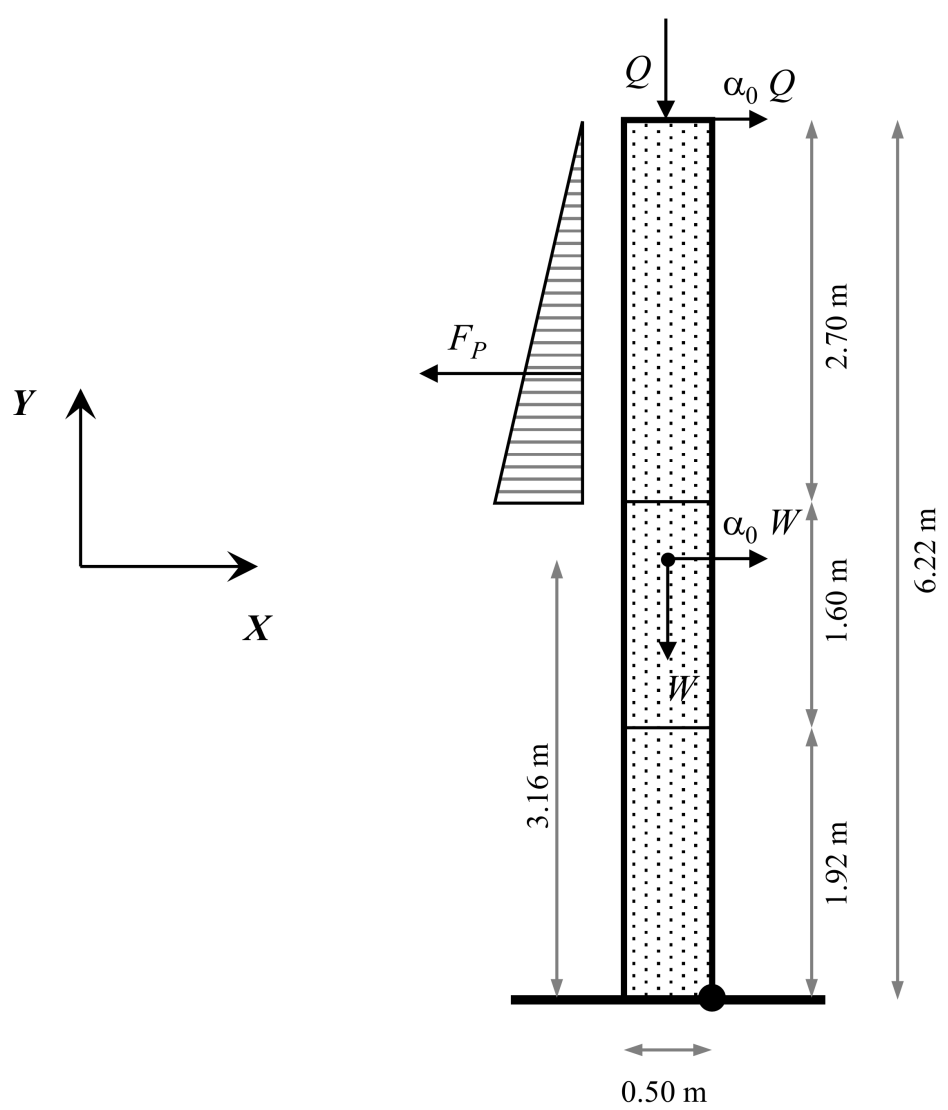

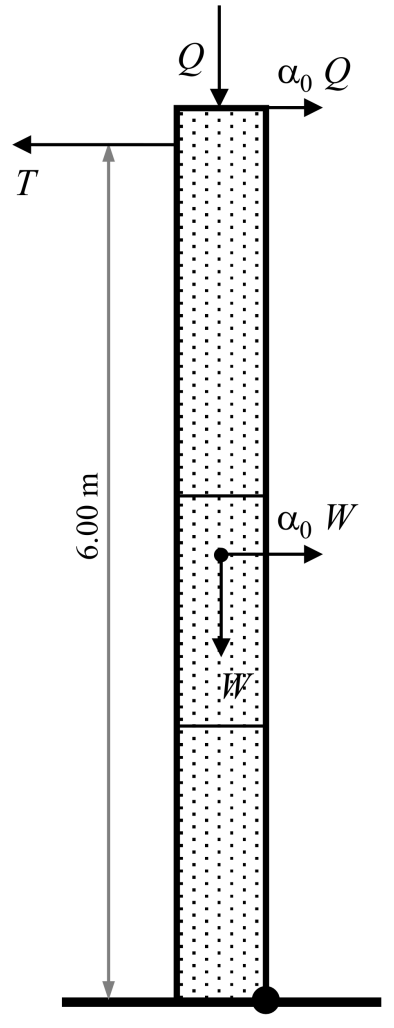

(b)

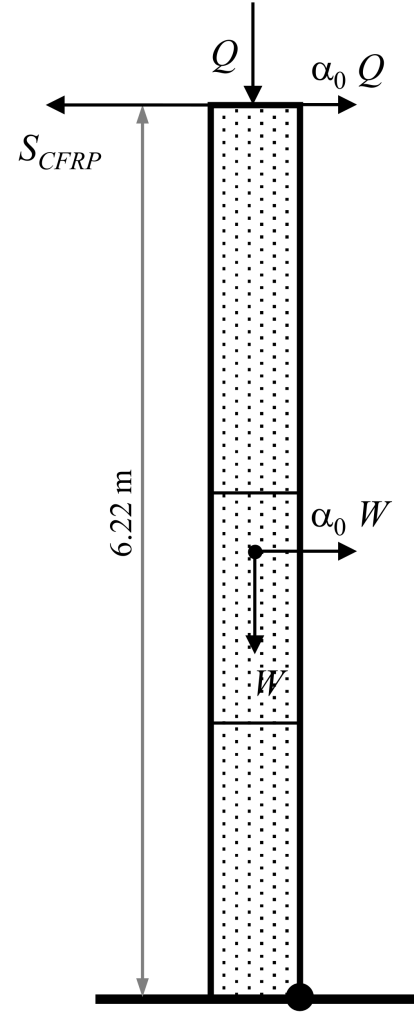

(c)

Figure 3. Forces and dimensions for the (a) unreinforced masonry wall (URW), (b) wall retrofitted with tie-rods (RWT) and (c) that with CFRP strips (RWS). 
The ultimate load multiplier $\alpha_{0}$ in Equation (6) can be calculated by means of the mentioned macro-block model [24,29], using either the principle of virtual works or the moment equilibrium of the wall portion under study. With reference to the three configurations sketched in Figure 3, the moment equilibrium with respect to the pivot point at the base of the wall will provide the generalized formulation (with the sum of all contributions):

$$
\alpha_{0}=\frac{(W+Q) x_{W}+2 F_{P} y_{F}+n_{T} T y_{T}+n_{S} S_{C F R P} y_{S}}{W y_{W}+Q y_{Q}},
$$

where the symbols represent:

- $\quad W$, the self-weight of the wall portion under study;

- $Q$, the overload applied to the wall top;

- $\quad x_{i}$, the horizontal distance between the application point of the $i$-th force and the pivot point;

- $\quad y_{i}$, the vertical distance between the application point of the $i$-th force and the pivot point;

- $\quad F_{P}$, the frictional resistance along one upper edge of the wall;

- $\quad T$, the pretension of the single tie-rod, $20 \%$ of the yielding force;

- $\quad S_{C F R P}$, the end debonding force provided by the single CFRP strip;

- $\quad n_{T}$, the number of tie-rods;

- $\quad n_{S}$, the number of CFRP strips.

Of course, the load multiplier and the related acceleration capacity for each wall configuration are evaluated by Equation (10), considering in turn the involved forces only.

The frictional resistance is assumed in its major contribution, as exerted by each adjacent wall along its upper part of $2.7 \mathrm{~m}$ height (Figure 3), through the formulation [25]:

$$
F_{P}=\gamma t h_{b} l_{b} \frac{n_{b}\left(n_{b}+1\right)}{4} f,
$$

where $\gamma$ is the specific weight of masonry, $t$ the thickness of the wall, $h_{b}$ and $l_{b}$ the height and length of the masonry unit, $n_{b}$ the number of courses within the upper wall portion, and $f$ the friction coefficient (Table 3 ). While the prestressing force of the single tie-rod can simply be evaluated as:

$$
T=20 \% f_{y d} A_{s},
$$

the contribution of the CFRP strips is assessed according to the Italian reference Guidelines CNR-DT 200 R1/2013 [53], which are currently one of the most reliable tools (at a design level) providing theoretical formulas for calculating the FRP contribution. Considering that this contribution depends on the tensile strength of masonry, significantly smaller than the tensile strengths of both the adhesive and the CFRP strip [58,59], the only debonding force is herein referred to, which can be calculated according to the expression:

$$
S_{C F R P}=\frac{b_{f}}{\gamma_{f, d}} \sqrt{2 E_{f} t_{f} \Gamma_{f}},
$$

where $b_{f}$ is the width of the CFRP strip, $\gamma_{f, d}$ is the partial safety factor, and $E_{f}$ and $t_{f}$ are the dry fibers Young's modulus and thickness (according to the technical data sheet), respectively. $\Gamma_{f}$ is the fracture energy defined as:

$$
\Gamma_{f}=\frac{k_{b} k_{G}}{C F} \sqrt{f_{b m} f_{b t m}}
$$

where $k_{b}$ and $k_{G}$ are the width and calibration factor, and $f_{b m}$ and $f_{b t m}$ are the brick mean compressive and tensile strength, respectively.

The forces acting on the wall are reported in Table 4 together with their lever arms $\left(x_{i}\right.$ and $\left.y_{i}\right)$, where it should be noted that $F_{P}, T$ and $S_{C F R P}$ are referred to single contributions. 
Considering the frictional resistance on both sides of the upper portion of the wall under study and $\gamma_{f, d}=1.25$ within Equation (13), the assessments provide a design number of $n_{T}=2$ orthogonal tie-rods with $22 \mathrm{~mm}$ in diameter and a design number of $n_{S}=4$ CFRP strips. The obtained load factors, spectral accelerations and seismic performance indicators are collected in Table 5. It is clear from this table that the seismic check by Equation (8) is not satisfied for the URW, while it turns guaranteed for the retrofitted configurations, whose seismic capacities increase by $140 \%$ with tie-rods reinforcement (RWT), and by $164 \%$ with CFRP strips reinforcement (RWS).

Table 4. Forces involved in the mechanism and their lever arms.

\begin{tabular}{ccc}
\hline Forces $(\mathbf{k N})$ & $\boldsymbol{x}_{\boldsymbol{i}} \mathbf{( \mathbf { m } )}$ & $\boldsymbol{y}_{\boldsymbol{i}}(\mathbf{m})$ \\
\hline$W=340.8$ & 0.25 & 3.16 \\
$Q=34.36$ & 0.25 & 6.22 \\
$F_{P}=10.37$ (Equation $\left.(11)\right)$ & - & 4.42 \\
$T=77.93$ (Equation (12)) & - & 6.00 \\
$S_{C F R P}=8.14$ (Equation (13)) & - & 6.22 \\
\hline
\end{tabular}

Table 5. Load factors, spectral accelerations, and seismic performance indicators for the URW and the designed RW configurations at ULS.

\begin{tabular}{cccccc}
\hline $\begin{array}{c}\text { Wall } \\
\text { Configuration }\end{array}$ & $\begin{array}{c}\boldsymbol{\alpha}_{0} \\
\text { (Equation (10)) }\end{array}$ & $\begin{array}{c}\boldsymbol{a}_{c}\left(\mathrm{~m} / \mathrm{s}^{\mathbf{2}}\right) \\
\text { (Equation (6)) }\end{array}$ & $\begin{array}{c}\boldsymbol{a}_{d}\left(\mathrm{~m} / \mathrm{s}^{\mathbf{2}}\right) \\
(\text { Equation (7)) }\end{array}$ & $\begin{array}{c}\Delta \boldsymbol{a}_{c} \\
\text { (Equation (1)) }\end{array}$ & $\begin{array}{c}\Delta \zeta \\
\text { (Equation (2)) }\end{array}$ \\
\hline URW & 0.144 & 1.50 & 2.98 & - & - \\
RWT $(2 T)$ & 0.294 & 3.07 & 2.98 & 1.05 & 1.06 \\
RWS $\left(4 S_{C F R P}\right)$ & 0.300 & 3.14 & 2.98 & 1.09 & 1.11 \\
\hline
\end{tabular}

The absolute seismic performance indicator $\Delta \zeta$ calculated with Equation (2) can be $<1$, since the Standards allow for existing building interventions that improve the seismic performance without fully meeting the Standards requirements valid for new buildings [46] (in any case, always ensuring $a_{c 1}>a_{c 0}$ where $a_{c 1}$ is the seismic capacity of the wall after the intervention).

\subsection{Thermal Analysis and Energy Performance Indicators}

The thermal analysis consists in calculating the thermal transmittance of IP. As mentioned earlier, in the case of CFRP strips and IP, the thermal transmittance can be further reduced by using less conductive material for plastering. However, it must be remarked that such a reduction is negligible in comparison with the reduction of the thermal transmittance assured by the IP itself. Therefore, this additional reduction has been disregarded in the analysis, thus making the effect of the thermal insulation independent on the strengthening intervention. Let us assume as the thermal insulation system the already-mentioned traditional polystyrene slab (density $20 \mathrm{~kg} / \mathrm{m}^{3}$ ), characterized, at a mean reference temperature of $10^{\circ} \mathrm{C}$, by a thermal conductivity $U=0.035 \mathrm{~W} /(\mathrm{m} \mathrm{K})[60]$. The thermal transmittance in the original configuration needs to be computed first. Procedures and equations utilized for computing the thermal transmittance are derived from [14]. Considering the layers of the masonry wall (inner lime plastering, limestone stone masonry of thickness $t=0.50 \mathrm{~m}$, external cement-based plastering) and the internal and external air-wall heat transfer convection coefficients, a value of thermal transmittance of the masonry wall $U_{m}=1.42 \mathrm{~W} \mathrm{~m}^{-2} \mathrm{~K}^{-1}$ is obtained. Then, considering the presence of two windows (Figure $2 b$ ), the weighted thermal transmittance in the original configuration $U_{0}=1.99 \mathrm{~W} \mathrm{~m}^{-2} \mathrm{~K}^{-1}$ is computed. The thermal transmittance demand $U_{d}$ is computed from the data provided in [61]. As the building is in a climate zone of type $\mathrm{C}$ (965 Degree days), the target demand thermal transmittances are $U_{d, \text { walls }}=0.36 \mathrm{~W} \mathrm{~m}^{-2} \mathrm{~K}^{-1}$ and $U_{d, \text { windows }}=2.00 \mathrm{~W} \mathrm{~m}^{-2} \mathrm{~K}^{-1}$ for walls and windows, respectively [61]. A consequent mean value of $U_{d}=0.56 \mathrm{~W} \mathrm{~m}^{-2} \mathrm{~K}^{-1}$ is obtained. The absolute energy performance indicator $\Delta \mathrm{Y}$ calculated with Equation (5) can be $<1$, also admitting as valid interventions that improve the energy performance without 
fully meeting the Standards requirements (in any case, always ensuring $U_{1}<U_{0}$ where $U_{1}$ is the thermal transmittance after the intervention).

\section{Case Study: Economic and Environmental Analyses and Iso-Cost Curves}

\subsection{Analysis in Terms of Seismic Performance Indicators}

\subsubsection{Economic Analysis}

In this paragraph, the seismic indicators are calculated as functions of the economic impact of the selected integrated interventions. Once again, only the installation phase is considered, whereas all the operations related to the usage (maintenance) and final disposal of the interventions are neglected. As explained in Section 3.3, the spectral acceleration demand is equal to $2.98 \mathrm{~m} / \mathrm{s}^{2}$ for the ultimate limit state. This value is approximated to $0.3 \mathrm{~g}$. For each integrated intervention (Section 3.2), six total economic budgets are fixed, in the range from 100 to $350 € / \mathrm{m}^{2}$, corresponding to different increases of the seismic and energetic performances. It is crystal clear that the seismic performance increase measured by $\Delta a_{c}$ has a relative significance. In fact, as already said, even if $\Delta a_{c}$ is extremely functional when the objective is the comparison of alternative solutions for a given building, it would lose its effectiveness when the benefit is referred to a specific demand, which depends on the site. For this reason, the iso-cost curves will be appropriately normalized by dividing the economic budget by the acceleration demand, which has been assumed as the reference seismic parameter. In addition, the second seismic performance parameter $\Delta \zeta$ has been considered to obtain a sounder estimation of the optimal integrated intervention.

In the analysis, the available target economic budget has been spent, suitably modifying the thickness of IP, the diameter of the steel tie-rods (a pair, $5 \mathrm{~m}$ long), and the number of the $1.5 \mathrm{~m}$ long and $0.2 \mathrm{~m}$ wide CFRP strips. Obviously, IP has been applied on the total net area of the masonry façade: $35.87 \mathrm{~m}^{2}$ (Figure $2 \mathrm{a}$ ).

An example of the computation of these indicators for CFRP strips and insulating panels is reported in Table 6 . The first seven rows of Table 6 report the calculation of energy performance indicators, while the last seven rows report the calculation of seismic performance indicators. Evidently, since the focus is on integrated interventions, the seismic performance indicator and the energy performance indicator should be considered together: for example, if IP improves the thermal behavior, the CFRP strips mainly enhance the seismic performance. It is important to recall that the sum of the two corresponding budgets (for example 2nd and 9th rows: $93.98 € / \mathrm{m}^{2}+6.02 € / \mathrm{m}^{2}=100 € / \mathrm{m}^{2}$ ) equals the target economic budget, ranging from $100 € / \mathrm{m}^{2}$ to $350 € / \mathrm{m}^{2}$, with a step of $50 € / \mathrm{m}^{2}$. Such a matching is obtained by varying the thickness $t_{I P}$ of IP and the number of CFRP strips. The current euro/dollar change is 1.16 according to the European Central Bank [62].

Table 6. Computation of thermal and seismic indicators for the integrated intervention with CFRP strips and insulating panels.

\begin{tabular}{|c|c|c|c|c|c|c|}
\hline Budget IP $\left(€ / \mathrm{m}^{2}\right)$ & $t_{I P}(\mathrm{~m})$ & Area $\left(m^{2}\right)$ & $\begin{array}{l}t_{I P} / \lambda=\mathrm{R} \\
\left(\mathrm{m}^{2} \mathrm{~K} / \mathrm{W}\right)\end{array}$ & $R_{1}\left(m^{2} K / W\right)$ & $\mathrm{U}_{1}\left(\mathrm{~W} / \mathrm{m}^{2} \mathrm{~K}\right)$ & $\Delta \mathbf{U}$ \\
\hline 93.98 & 0.049 & 40.862 & 1.237 & 1.738 & 0.575 & $71 \%$ \\
\hline 140.97 & 0.074 & 40.862 & 1.855 & 2.356 & 0.424 & $79 \%$ \\
\hline 187.96 & 0.099 & 40.862 & 2.473 & 2.975 & 0.336 & $83 \%$ \\
\hline 234.95 & 0.124 & 40.862 & 3.091 & 3.593 & 0.278 & $86 \%$ \\
\hline 281.94 & 0.148 & 40.862 & 3.710 & 4.211 & 0.237 & $88 \%$ \\
\hline 328.93 & 0.173 & 40.862 & 4.328 & 4.830 & 0.207 & $90 \%$ \\
\hline $\begin{array}{c}\text { Budget CFRP } \\
\left(€ / \mathrm{m}^{2}\right)\end{array}$ & $n_{s}$ & Cost & $\operatorname{Cos} t / \mathrm{m}^{2}$ & $a_{c, 0}\left(\mathrm{~m} / \mathrm{s}^{2}\right)$ & $a_{c, 1}\left(\mathrm{~m} / \mathrm{s}^{2}\right)$ & $\Delta a_{c}$ \\
\hline 6.02 & 2 & 246.00 & 6.02 & 1.50 & 2.32 & $55 \%$ \\
\hline 9.03 & 3 & 369.00 & 9.03 & 1.50 & 2.73 & $82 \%$ \\
\hline 12.04 & 4 & 492.00 & 12.04 & 1.50 & 3.14 & $109 \%$ \\
\hline 15.05 & 5 & 615.00 & 15.05 & 1.50 & 3.55 & $137 \%$ \\
\hline 18.06 & 6 & 738.00 & 18.06 & 1.50 & 3.96 & $164 \%$ \\
\hline 21.07 & 7 & 861.00 & 21.07 & 1.50 & 4.37 & $191 \%$ \\
\hline
\end{tabular}


For what concerns the seismic analysis, the initial seismic performance indicator is the acceleration capacity in the original configuration, $a_{c, 0}$, which equals $1.50 \mathrm{~m} / \mathrm{s}^{2}$, being evidently independent of the seismic demand. In contrast, the post-retrofitting acceleration capacity, $a_{c, 1}$, obviously varies as a function of the number of CFRP strips. The two values of acceleration capacity are then used in Equation (1) to compute the relative increase of acceleration capacity $\Delta a_{c}$. Analogous considerations can be made for the integrated intervention, combining IP with tie-rods of variable number and diameter (Table 7).

Table 7. Computation of thermal and seismic indicators for the integrated intervention with tie-rods and insulating panels.

\begin{tabular}{|c|c|c|c|c|c|c|}
\hline Budget IP $\left(€ / \mathrm{m}^{2}\right)$ & $t_{I P}(\mathrm{~m})$ & Area $\left(m^{2}\right)$ & $\begin{array}{l}t_{I P} / \lambda=\mathrm{R} \\
\left(\mathrm{m}^{2} \mathrm{~K} / \mathrm{W}\right)\end{array}$ & $R_{1}\left(m^{2} K / W\right)$ & $\mathrm{U}_{1}\left(\mathrm{~W} / \mathrm{m}^{2} \mathrm{~K}\right)$ & $\Delta \mathbf{U}$ \\
\hline 88.26 & 0.046 & 40.862 & 1.161 & 1.663 & 0.601 & $70 \%$ \\
\hline 137.52 & 0.072 & 40.862 & 1.810 & 2.311 & 0.433 & $78 \%$ \\
\hline 187.91 & 0.099 & 40.862 & 2.473 & 2.974 & 0.336 & $83 \%$ \\
\hline 237.01 & 0.125 & 40.862 & 3.119 & 3.620 & 0.276 & $86 \%$ \\
\hline 287.53 & 0.151 & 40.862 & 3.783 & 4.285 & 0.233 & $88 \%$ \\
\hline 336.44 & 0.177 & 40.862 & 4.427 & 4.928 & 0.203 & $90 \%$ \\
\hline $\begin{array}{l}\text { Budget Tie-Rods } \\
\qquad\left(€ / \mathrm{m}^{2}\right)\end{array}$ & $n_{T} \times d$ & Cost & Cost $/ \mathrm{m}^{2}$ & $a_{c, 0}\left(\mathrm{~m} / \mathrm{s}^{2}\right)$ & $a_{c, 1}\left(\mathrm{~m} / \mathrm{s}^{2}\right)$ & $\Delta a_{c}$ \\
\hline 11.74 & $2 \times 18 \mathrm{~mm}$ & 479.90 & 11.74 & 1.50 & 2.55 & $70 \%$ \\
\hline 12.48 & $3 \times 18 \mathrm{~mm}$ & 509.85 & 12.48 & 1.50 & 3.07 & $105 \%$ \\
\hline 12.09 & $2 \times 20 \mathrm{~mm}$ & 493.95 & 12.09 & 1.50 & 2.80 & $86 \%$ \\
\hline 12.99 & $3 \times 20 \mathrm{~mm}$ & 530.92 & 12.99 & 1.50 & 3.45 & $130 \%$ \\
\hline 12.47 & $2 \times 22 \mathrm{~mm}$ & 509.48 & 12.47 & 1.50 & 3.07 & $105 \%$ \\
\hline 13.56 & $3 \times 22 \mathrm{~mm}$ & 554.21 & 13.56 & 1.50 & 3.85 & $157 \%$ \\
\hline
\end{tabular}

The summary of the results for all the integrated interventions is reported in Table 8 . The minimum number of CFRP strips that verifies the seismic analysis is $4\left(\Delta a_{c}=1.09\right.$; $\Delta \zeta=1.11>1)$. The minimum number and diameter of tie-rods which guarantee safety is $3 \times 18,3 \times 20$, or $2 \times 22 \mathrm{~mm}$. These two structural retrofitting techniques should be coupled with at least $7 \mathrm{~cm}$ thick IP $(\Delta \mathrm{Y}>1)$ to attain the target thermal transmittance $U_{d}=0.56 \mathrm{~W} \mathrm{~m}^{-2} \mathrm{~K}^{-1}$ (Section 3.4).

Table 8. Acceleration capacity and seismic performance indicators for each integrated intervention $\left(\mathrm{IP}=\right.$ insulating panels, $d_{\text {const }}=$ constant diameter of tie-rods $)$ —economic analysis .

\begin{tabular}{cccccccccc}
\hline & \multicolumn{3}{c}{ Tie-Rods $d_{\text {const }}+\mathbf{I P}$} & \multicolumn{3}{c}{ Tie-Rods $\boldsymbol{d}_{\text {variable }}+$ IP } & \multicolumn{3}{c}{ CFRP + IP } \\
\hline Budget $\left(\boldsymbol{\epsilon} / \mathbf{m}^{\mathbf{2}}\right)$ & $\boldsymbol{a}_{\boldsymbol{c}, 1}\left(\mathbf{m} / \mathbf{s}^{\mathbf{2}}\right)$ & $\boldsymbol{\Delta} \boldsymbol{a}_{\boldsymbol{c}}$ & $\boldsymbol{\Delta} \boldsymbol{\zeta}$ & $\boldsymbol{a}_{\boldsymbol{c}, 1} \mathbf{( \mathbf { m } / \mathbf { s } ^ { \mathbf { 2 } } )}$ & $\boldsymbol{\Delta} \boldsymbol{a}_{\boldsymbol{c}}$ & $\boldsymbol{\Delta} \boldsymbol{\zeta}$ & $\boldsymbol{a}_{\boldsymbol{c}, 1}\left(\mathbf{m} / \mathbf{s}^{\mathbf{2}}\right)$ & $\boldsymbol{\Delta} \boldsymbol{a}_{\boldsymbol{c}}$ & $\boldsymbol{\Delta} \boldsymbol{\zeta}$ \\
\hline 100 & 3.07 & 1.05 & 1.06 & 2.55 & 0.70 & 0.71 & 2.32 & 0.55 & 0.56 \\
150 & 3.07 & 1.05 & 1.06 & 3.07 & 1.05 & 1.06 & 2.73 & 0.82 & 0.83 \\
200 & 3.07 & 1.05 & 1.06 & 2.80 & 0.86 & 0.88 & 3.14 & 1.09 & 1.11 \\
250 & 3.07 & 1.05 & 1.06 & 3.45 & 1.30 & 1.32 & 3.55 & 1.37 & 1.39 \\
300 & 3.07 & 1.05 & 1.06 & 3.07 & 1.05 & 1.06 & 3.96 & 1.64 & 1.66 \\
350 & 3.07 & 1.05 & 1.06 & 3.85 & 1.57 & 1.59 & 4.37 & 1.91 & 1.94 \\
\hline
\end{tabular}

It is worthy to notice that in all integrated interventions, the removal of old plaster and the new plastering are considered in the cost assessment.

\subsubsection{Environmental Analysis}

In this paragraph, the seismic indicators are calculated as functions of the environmental impact of the selected integrated interventions. The environmental analysis is performed under the same assumptions already adopted in Section 4.1.1, again considering only the installation phase, and disregarding other phases of the LCCA.

For each integrated intervention (Section 3.2), four environmental emission thresholds are fixed, from 20 to $50 \mathrm{kgCO} 2 \mathrm{eq} / \mathrm{m}^{2}$. In the corresponding iso-cost curves, the environmental impact is divided by the acceleration demand $\left(a_{d}=0.3 \mathrm{~g}\right)$, again to normalize the results in terms of the reference seismic parameter. Analogously to the economic analysis, 
thickness of IP, diameter, and number of $5 \mathrm{~m}$ long tie-rods and number of CFRP strips (length $1.5 \mathrm{~m}$, width $0.20 \mathrm{~m}$ ) have been varied to match the target environmental budget. For the sake of brevity, only the final results are listed in Table 9. It summarizes the seismic enhancement for each carbon footprint level (in $\mathrm{kgCO}_{2} \mathrm{eq} / \mathrm{m}^{2}$ ) normalized per square meter of the total wall area. It is worthy to notice that three tie-rods with $\mathrm{d}=18 \mathrm{~mm}$ are the minimum required solution $(\Delta \zeta=1.07)$, providing an improvement of acceleration capacity by $105 \%$ (third column of Table 9 ). When the tie-rod diameter is variable (fifth, sixth, and seventh column), the seismic improvement increases from $70 \%$, corresponding to two ties with $d=18 \mathrm{~mm}$ and $6 \mathrm{~cm}$ thick insulating panels, up to $130 \%$, when three $d=20 \mathrm{~mm}$ ties and $14 \mathrm{~cm}$ thick insulating panels are implemented. In all the considered cases, the tie-rods, $5 \mathrm{~m}$ long, have been hypothesized to be placed at the top of the wall (Table 4).

Table 9. Acceleration capacity and seismic performance indicators for each integrated intervention $\left(\mathrm{IP}=\right.$ insulating panels, $d_{\text {const }}=$ constant diameter of tie-rods $)$ —environmental analysis.

\begin{tabular}{|c|c|c|c|c|c|c|c|c|c|}
\hline \multirow[b]{2}{*}{$\begin{array}{l}\text { Carbon Footprint } \\
\left(\mathrm{kgCO}_{2} \mathrm{eq} / \mathrm{m}^{2}\right)\end{array}$} & \multicolumn{3}{|c|}{ Tie-Rods $d_{\text {const }}+$ IP } & \multicolumn{3}{|c|}{ Tie-Rods $d_{\text {variable }}+$ IP } & \multicolumn{3}{|c|}{ CFRP + IP } \\
\hline & $a_{c, 1}\left(\mathrm{~m} / \mathrm{s}^{2}\right)$ & $\Delta a_{c}$ & $\Delta \zeta$ & $a_{c, 1}\left(\mathrm{~m} / \mathrm{s}^{2}\right)$ & $\Delta a_{c}$ & $\Delta \zeta$ & $a_{c, 1}\left(\mathrm{~m} / \mathrm{s}^{2}\right)$ & $\Delta a_{c}$ & $\Delta \zeta$ \\
\hline 20 & 3.07 & 1.05 & 1.07 & 2.55 & 0.70 & 0.71 & 2.32 & 0.55 & 0.56 \\
\hline 30 & 3.07 & 1.05 & 1.07 & 3.07 & 1.05 & 1.06 & 1.50 & 0.82 & 0.83 \\
\hline 40 & 3.07 & 1.05 & 1.07 & 2.80 & 0.86 & 0.88 & 1.50 & 1.09 & 1.11 \\
\hline 50 & 3.07 & 1.05 & 1.07 & 3.45 & 1.30 & 1.32 & 1.50 & 1.37 & 1.39 \\
\hline
\end{tabular}

In the integrated intervention based on tie-rods, only a minimal part (about $2 \%$ ) of carbon footprint refers to the tie-rods themselves. In fact, the majority of carbon footprint regards the insulating panels, which have a unit environmental impact of $343 \mathrm{kgCO}_{2} \mathrm{eq} / \mathrm{m}^{3}$. A similar consideration can be made for the intervention with CFRP strips and IP (last three columns of Table 9), although, in this case, the impact of the CFRP strips is a little higher, $3.5 \%$ on average. For this integrated intervention, the seismic impact increases from $55 \%$, corresponding to two CFRP stripes, $1.5 \mathrm{~m}$ long and $0.2 \mathrm{~m}$ wide, associated with $6 \mathrm{~cm}$ thick insulating panels, up to $137 \%$, when the number of the CFRP stripes is increased to five and the thickness of the insulating panels is $140 \mathrm{~mm}$.

\subsection{Analysis in Terms of Energy Performance Indicators}

\subsubsection{Economic Analysis}

The economic analysis considering energy performance indicators is computed in the same way as illustrated in Section 4.1 for the seismic analysis. The summary of the results for all the integrated interventions is listed in Table 10. They are computed tuning thickness of IP, number and diameter of tie-rods, and number of CFRP strips.

Table 10. Thermal resistance and energy performance indicators for each integrated interventioneconomic analysis.

\begin{tabular}{ccccccccccccc}
\hline & & IP & \multicolumn{4}{c}{ Tie-Rods $d_{\text {const }}+$ IP } & \multicolumn{3}{c}{ Tie-Rods $d_{\text {variable }}+$ IP } & \multicolumn{3}{c}{ CFRP + IP } \\
\hline Budget $\left(\mathbf{f} / \mathbf{m}^{2}\right)$ & $\boldsymbol{U}_{1}$ & $\boldsymbol{\Delta} \boldsymbol{U}$ & $\boldsymbol{\Delta} \mathbf{Y}$ & $\boldsymbol{U}_{1}$ & $\boldsymbol{\Delta} \boldsymbol{U}$ & $\boldsymbol{\Delta} \mathbf{Y}$ & $\boldsymbol{U}_{1}$ & $\boldsymbol{\Delta} \boldsymbol{U}$ & $\boldsymbol{\Delta Y}$ & $\boldsymbol{U}_{1}$ & $\boldsymbol{\Delta} \boldsymbol{U}$ & $\boldsymbol{\Delta} \mathbf{Y}$ \\
\hline 100 & 0.49 & 0.75 & 1.05 & 0.60 & 0.70 & 0.97 & 0.60 & 0.70 & 0.97 & 0.58 & 0.71 & 0.99 \\
150 & 0.37 & 0.81 & 1.13 & 0.43 & 0.78 & 1.09 & 0.43 & 0.78 & 1.09 & 0.42 & 0.79 & 1.10 \\
200 & 0.30 & 0.85 & 1.18 & 0.34 & 0.83 & 1.16 & 0.34 & 0.83 & 1.16 & 0.34 & 0.83 & 1.16 \\
250 & 0.25 & 0.87 & 1.22 & 0.28 & 0.86 & 1.20 & 0.28 & 0.86 & 1.20 & 0.28 & 0.86 & 1.20 \\
300 & 0.21 & 0.89 & 1.24 & 0.23 & 0.88 & 1.23 & 0.23 & 0.88 & 1.23 & 0.24 & 0.88 & 1.23 \\
350 & 0.19 & 0.91 & 1.26 & 0.20 & 0.90 & 1.25 & 0.20 & 0.90 & 1.25 & 0.21 & 0.90 & 1.25 \\
\hline
\end{tabular}

In Table 10, the values of the thermal transmittance and the two energy performance indicators are listed as functions of the intervention, namely, insulating panels only, or integrated intervention combining insulating panels, in turn, with steel tie-rods having constant or variable diameter, or with CFRP strips. Increasing the economic budget, the 
thermal transmittance clearly decreases, guaranteeing an improvement in the energy performance of the wall. Implementing the IP alone, the percentage reduction of thermal transmittance $\Delta U$ goes from around $75 \%$ for the $100 € / \mathrm{m}^{2}$ budget $(50 \mathrm{~mm}$ thick insulating panels) to around $91 \%$ for the $350 € / \mathrm{m}^{2}$ budget $(180 \mathrm{~cm}$ thick insulating panels). The corresponding absolute decrements $\Delta \mathrm{Y}$ are 1.05 and 1.26, respectively. Thus, even the lowest budget guarantees an effective intervention satisfying the target thermal transmittance. The trend of both energy performance indicators is not linear with the economic cost; in fact, the benefit obtained increasing the budget by a fixed amount, $50 € / \mathrm{m}^{2}$, decreases as the total budget increases. As anticipated, the tie-rods do not influence the variation of thermal transmittance, while the final plastering is already included in the intervention with the IP alone. Evidently, for a given budget, integrated interventions lead to reductions of the thermal transmittance lower than those obtained with IP only, as part of the economic budget is devoted to the realization of the structural strengthening. Since the ratio between structural and energy saving costs depends on the adopted structural intervention, this effect is more pronounced for tie-rods rather than CFRP, if the considered budget is the lowest, the contrary occurs increasing the budget.

\subsubsection{Environmental Analysis}

The environmental analysis follows the procedure utilized for the economic analysis. The only difference is that the impact of each integrated intervention is computed as a function of the carbon footprint rather than the economic cost. Table 11 reports the achieved values of the thermal transmittance and the energy performance indicators, depending on the type of intervention and on the carbon footprint, expressed in terms of carbon dioxide emissions for unit area of the wall. Examining the data of Table 11, it clearly results that small energy savings can imply high environmental impacts: for example, when the intervention consists in the application of insulating panels only, doubling the carbon footprint, from $20 \mathrm{kgCO} 2 \mathrm{eq} / \mathrm{m}^{2}$ (60 mm thick IP) to $40 \mathrm{kgCO}{ }_{2} \mathrm{eq} / \mathrm{m}^{2}$ (120 mm thick IP), results in a small reduction, less than $10 \%$, of thermal transmittance (3rd column of Table 11). Looking at the absolute performance indicator $\Delta \mathrm{Y}$, the wiser choice would be to limit as much as possible the environmental impact, selecting a $90 \mathrm{~mm}$ thick IP corresponding to $30 \mathrm{kgCO} 2 \mathrm{eq} / \mathrm{m}^{2}$. Moreover, as expected, the integrated interventions adopting steel tierods of constant diameter (three ties, $5 \mathrm{~m}$ long, and $18 \mathrm{~mm}$ in diameter), or CFRP strips in association with IP, achieve lower benefits, in terms of reduction of thermal transmittance, in comparison with the IP intervention. In fact, as already explained for the economic analysis, part of the environmental impact is due to the, although minimal, environmental impact of the structural intervention (steel ties or CFRP strips). Consequently, if the energy performance requirements are not particularly strict, sustainable interventions call for limiting as much as possible the thickness of the insulating panels.

Table 11. Thermal resistance and energy performance indicators for each integrated interventionenvironmental analysis.

\begin{tabular}{cccccccccccccccc}
\hline & & $\mathbf{I P}$ & \multicolumn{4}{c}{ Tie-Rods $d_{\text {const }}+\mathbf{I P}$} & \multicolumn{2}{c}{ Tie-Rods $d_{\text {variable }}+\mathbf{I P}$} & \multicolumn{3}{c}{ CFRP + IP } \\
\hline $\begin{array}{c}\text { Carbon Footprint } \\
\left(\mathbf{k g C O} \mathbf{e q}_{\mathbf{m}} \mathbf{m}^{\mathbf{2}}\right)\end{array}$ & $\boldsymbol{U}_{1}$ & $\boldsymbol{\Delta} \boldsymbol{U}$ & $\boldsymbol{\Delta} \mathbf{Y}$ & $\boldsymbol{U}_{1}$ & $\boldsymbol{\Delta} \boldsymbol{U}$ & $\boldsymbol{\Delta} \mathbf{Y}$ & $\boldsymbol{U}_{1}$ & $\boldsymbol{\Delta} \boldsymbol{U}$ & $\boldsymbol{\Delta} \mathbf{Y}$ & $\boldsymbol{U}_{1}$ & $\boldsymbol{\Delta} \boldsymbol{U}$ & $\boldsymbol{\Delta} \mathbf{Y}$ \\
\hline 20 & 0.46 & 0.77 & 0.94 & 0.52 & 0.74 & 0.90 & 0.52 & 0.74 & 0.90 & 0.53 & 0.73 & 0.90 \\
30 & 0.35 & 0.83 & 1.01 & 0.38 & 0.81 & 0.99 & 0.38 & 0.81 & 0.99 & 0.38 & 0.81 & 0.99 \\
40 & 0.28 & 0.86 & 1.05 & 0.30 & 0.85 & 1.04 & 0.30 & 0.85 & 1.04 & 0.30 & 0.85 & 1.04 \\
50 & 0.23 & 0.88 & 1.08 & 0.24 & 0.88 & 1.07 & 0.24 & 0.88 & 1.07 & 0.25 & 0.88 & 1.07 \\
\hline
\end{tabular}

\subsection{Economic and Environmental Iso-Cost Curves}

This subsection discusses the iso-cost curves derived combining the two pairs of seismic and energy performance indicators: $\Delta a_{c}-\Delta U$ (relative) and $\Delta \zeta-\Delta \mathrm{Y}$ (absolute). 


\subsubsection{Relative Seismic and Energy Performance Indicators}

Since the structural benefits of a given intervention depend on the demand, i.e., the peak ground acceleration (PGA), and, consequently, on the site, to improve the significance of the analysis, the economic budgets should be normalized in terms of demand, in case the relative indicators are plotted. In the following, the curves are normalized in terms of the PGA of the reference construction site, expressed in $\mathrm{g}(\mathrm{PGA} U \mathrm{ULS}=0.30 \mathrm{~g})$. In this way, the seismic and energy performance indicators, listed in Tables 8 and 9 (seismic analysis) and in Tables 10 and 11 (thermal analysis), and the economic and environmental iso-cost normalized curves shown in Figures 4 and 5, respectively, have been derived. These curves thus allow obtaining the cost assessed for each integrated intervention by simply multiplying the values of the legend by the acceleration demand of the actual site.

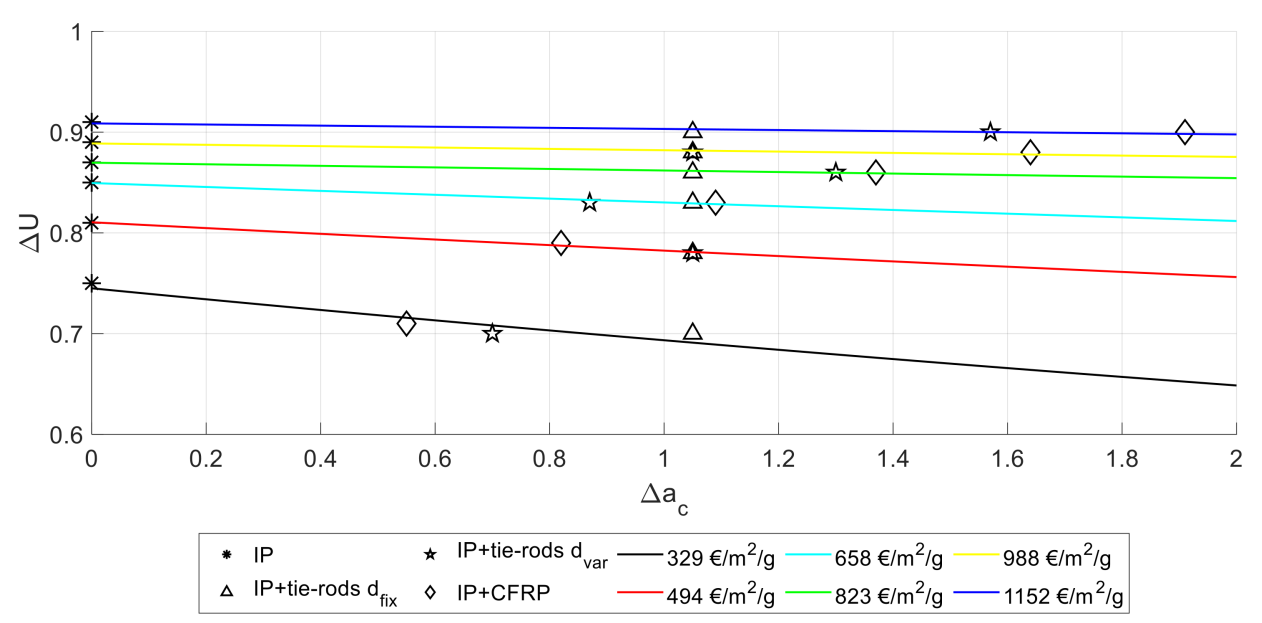

Figure 4. Economic iso-cost curves-relative performance indicators $\Delta U$ (thermal) $-\Delta a_{c}$ (seismic) for different integrated retrofit solutions and consequent fitting curves as function of the economic budget.

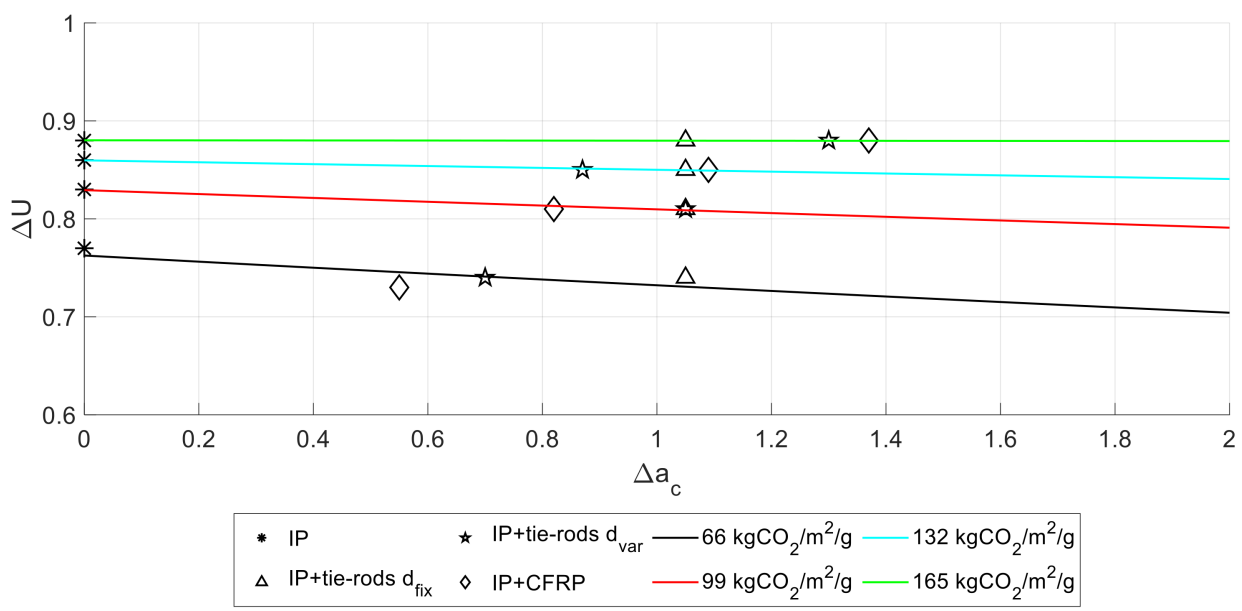

Figure 5. Environmental iso-cost curves-relative performance indicators $\Delta U$ (thermal) $-\Delta a_{c}$ (seismic) for different integrated retrofit solutions and consequent fitting curves as function of the environmental impact.

Firstly, the single indicators (pair $\Delta U-\Delta a_{c}$ ) are marked in the graph for each economic budget (trivially, the higher the economic budget, the greater the two values of $\Delta U-\Delta a_{c}$ ). Recalling what is illustrated in Section 2.5, for each considered integrated solution, the procedure is repeated $n=6$ times, $n$ being the number of the investigated levels, in terms of economic budget. Consequently, $i=4$ is the number of the integrated solutions considered in the analysis, and each graph counts $i \times n=24$ scattered combined indicators. 
The iso-cost curves are then drawn with the minimum least square criterion. These curves can be used by decision makers in a two-way strategy, depending on the criterion governing the choice:

- $\quad$ when the economic budget is given, to identify the optimum integrated intervention, by determining the corresponding pair $\Delta U-\Delta a_{c}$ (for example by means of demand curves [14]);

- when the pair $\Delta U-\Delta a_{c}$ is given, to determine the economic budget to be allocated, by determining the iso-cost curve passing by $\Delta U-\Delta a_{c}$.

\subsubsection{Absolute Seismic and Energy Performance Indicators}

The absolute seismic and energy performance indicators $\Delta \zeta-\Delta \mathrm{Y}$ provide a more complete information for the specific considered case as they include the acceleration demand. The economic and environmental iso-cost curves shown in Figures 6 and 7 have been derived, respectively, again using the data reported in Tables 8 and 9 (seismic analysis) and in Tables 10 and 11 (thermal analysis). In this case, the legend is simply expressed as unit economic and environmental costs, the demand being already included in the indicators' values. Thus, these curves are more readable when a single case must be evaluated.

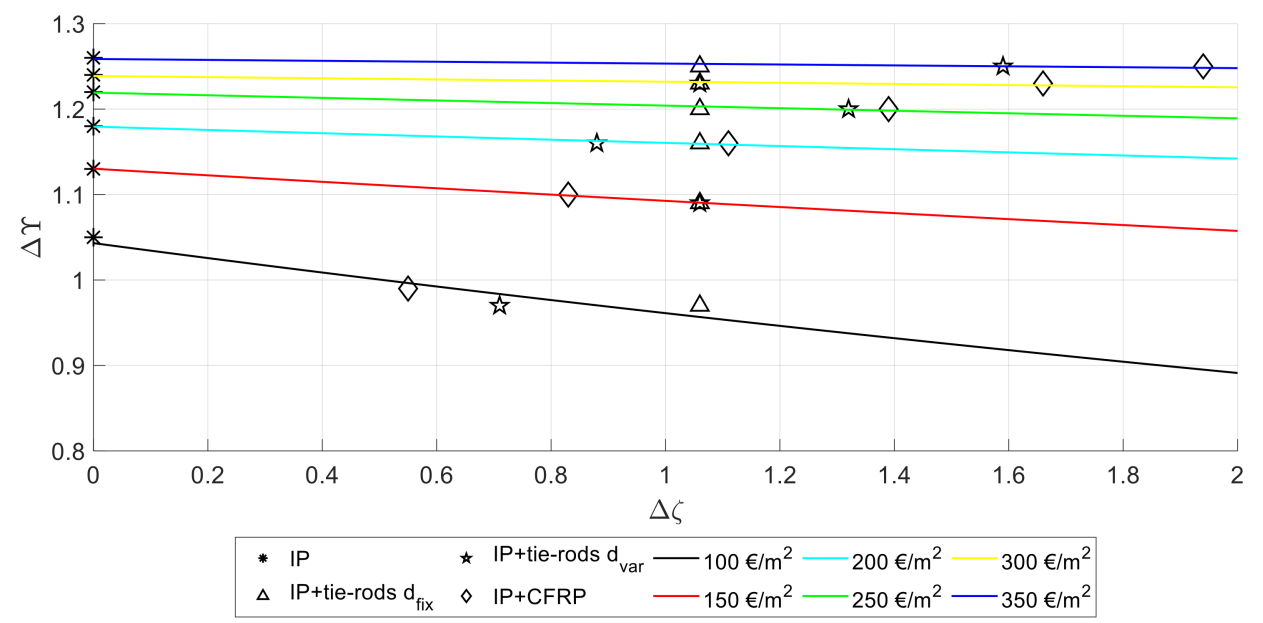

Figure 6. Economic iso-cost curves-absolute performance indicators $\Delta \mathrm{Y}$ (thermal) $-\Delta \zeta$ (seismic) for different integrated retrofit solutions and consequent fitting curves as function of the economic budget.

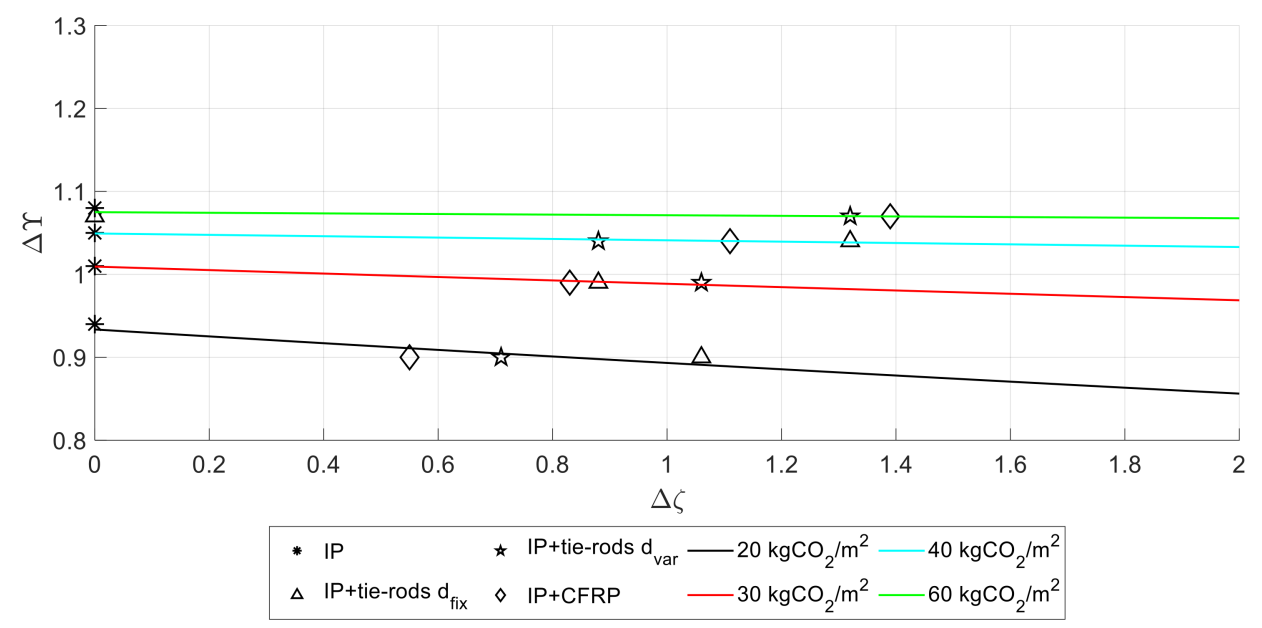

Figure 7. Environmental iso-cost curves-absolute performance indicators $\Delta \mathrm{Y}$ (thermal) $-\Delta \zeta$ (seismic) for different integrated retrofit solutions and consequent fitting curves as function of the environmental impact. 
Analogously to the iso-cost curves plotting the relative indicators, these graphs can be read by fixing the economic/environmental admissible impact and finding the optimal integrated intervention. As an alternative, the pair $\Delta Y-\Delta \zeta$ can be assigned and the corresponding budget consequently determined.

\section{Discussion}

The paper suggests a new methodology to assess the optimal integrated intervention with reference to retrofitting solutions counteracting out-of-plane (OOP) failure modes in existing masonry buildings. The fundamental step consists in defining sound seismic and energy performance indicators, which are, respectively:

- $\quad \Delta a_{c} ; \Delta \zeta$ for the seismic analysis;

- $\quad \Delta U ; \Delta \mathrm{Y}$ for the thermal analysis.

The first ones give a measure of the safety increment attained in terms of acceleration and thermal transmittance capacity; the second ones complete the information correlating the capacity to the seismic and energetic demands.

A typical OOP mode of simple overturning around a cylindrical horizontal hinge has been considered for a relevant case study, extrapolated from an existing masonry school located in Southern Italy.

Three basic solutions, combined into integrated interventions, have been hypothesized: insulating panels (IP), a variable number of $5 \mathrm{~m}$ long steel tie-rods, characterized by fixed or varying diameter, and a variable number of $1.5 \mathrm{~m}$ long and $0.2 \mathrm{~m}$ wide CFRP strips. The target economic budget has been then saturated suitably modifying the thickness of IP, the diameter of tie-rods, and the number of CFRP strips.

A suitable economic analysis has been performed considering budgets ranging from 100 to $350 € / \mathrm{m}^{2}$, corresponding to different increases of the seismic and energetic performances. For each integrated intervention, the absolute thermal and seismic indicators $\Delta \mathrm{Y}$ and $\Delta \zeta$ has been computed, revealing that the minimum retrofitting solutions that verify the required conditions consist in a $70 \mathrm{~mm}$ thick insulating panel, coupled with three tie rods, if their diameter is 18 or $20 \mathrm{~mm}$, or with two $22 \mathrm{~mm}$ diameter tie-rods, or, as an alternative, with four CFRP strips. The intervention that implies higher variability of the seismic performance indicator (abscissa axes of Figures 4-7) is that with CFRP strips and IP. The energy performance indicators show that small energy savings could imply too-high environmental impacts. For example, when the intervention consists in the application of insulating panels only, doubling the carbon footprint, from 66 to $132 \mathrm{kgCO}_{2} \mathrm{eq} / \mathrm{m}^{2}$, will result in a reduction of the thermal transmittance smaller than 10\% (Figure 5). The same occurs when integrated interventions are considered. For example, for both integrated interventions with CFRP strips and IP and tie-rods and IP, passing from 30 to $50 \mathrm{kgCO}{ }_{2} \mathrm{eq} / \mathrm{m}^{2}$ only causes a negligible increase of the absolute thermal performance indicator, from 0.99 to 1.07 (Figure 7). It means that the difference by $20 \mathrm{kgCO} 2 \mathrm{eq} / \mathrm{m}^{2}$ emitted in the atmosphere would be useless since with $30 \mathrm{kgCO} 2 \mathrm{eq} / \mathrm{m}^{2}$ one would have an intervention meeting the thermal requirements $(0.99 \approx 1)$. These considerations make it necessary to assess the carbon footprint of each intervention in order to avoid unnecessary high environmental impacts. Consequently, if the energy performance requirements are not particularly strict, sustainable interventions call for limiting as much as possible the thickness of the insulating panels, also cosidering that the environmental impact of structural interventions (steel ties or CFRP strips) is not particularly significant.

The iso-cost curves, either considering relative or absolute seismic and energy performance indicators, can be a very powerful tool to compare different solutions. Iso-cost curves in terms of absolute indicators are more suitable for assessing effects of varying acceleration demands on a given building, while iso-cost curves in terms of relative indicators are more readable, when a plurality of cases, located in different sites, needs to be evaluated. Both types of curves are two-way readable: by fixing the economic/environmental admissible impact, the optimal integrated intervention is found. As an alternative, the 
pair of seismic and energy performance indicators can be assigned, and the corresponding budget consequently determined.

It is worth comparing the suggested methodology with models already available in the literature. Such models were recently presented for the optimization of integrated interventions, enhancing the performance of in-plane modes in masonry buildings $[12,14,63]$. In the methodology illustrated in [14,63], the target point is given by the intersection of the capacity curve with the demand curve (Figure 8 ). The demand curve, defined for a specific building site, is a function of seismic and energy parameters of the site through the following expression [14]:

$$
\Delta U=\alpha \frac{c_{R}}{c_{U}} \Delta V,
$$

where $\Delta V$ is the seismic performance indicator in terms of base shear (significant for inplane modes) and the coefficient $\alpha$ is a tuning parameter established by the decision-maker. The two dimensionless parameters $c_{U}$ and $c_{R}$ depend on the site location according to the number of degree day (DD) and to the peak ground acceleration PGA of the site, respectively [12]:

$$
c_{U}=\frac{D D_{i}}{D D_{\max }} ; c_{R}=\frac{P G A_{i}}{P G A_{\max }},
$$

where $P G A_{\max }$ and $D D_{\max }$ are the maximum values of PGA and degree day, respectively, in the reference area (regional, national, or other). That methodology is clearly different, albeit similar, from that proposed in this paper. Indeed, in [14], the capacity is not correlated with the site parameters, and this could be limiting, especially in the seismic vulnerability assessment, where the safety verifications indicated by the Standards [64] involve complex relationships between the acceleration, or displacement, capacity and the acceleration, or displacement, demand. By contrast, the suggested methodology directly considers the actual demand of the site (Figure 7). In fact, the graph of absolute performance indicators $\Delta \zeta-\Delta \mathrm{Y}$ gives complete information about the impact corresponding to the minimum safety coefficients, because $\Delta \zeta$ and $\Delta \mathrm{Y}$ are also functions of the demand. In other words, with the suggested methodology, one can directly read in the curves plotting absolute performance indicators the environmental and the economic impact for a given site corresponding to safety coefficients at least equal to 1 , which is the minimum for which all the verifications are satisfied. The safety coefficients can be tuned according to the needs of the decision maker, for example, giving greater relevance to the seismic safety than the energy performance, selecting $\Delta \zeta>\Delta \mathrm{Y} \geq 1$, or vice versa.

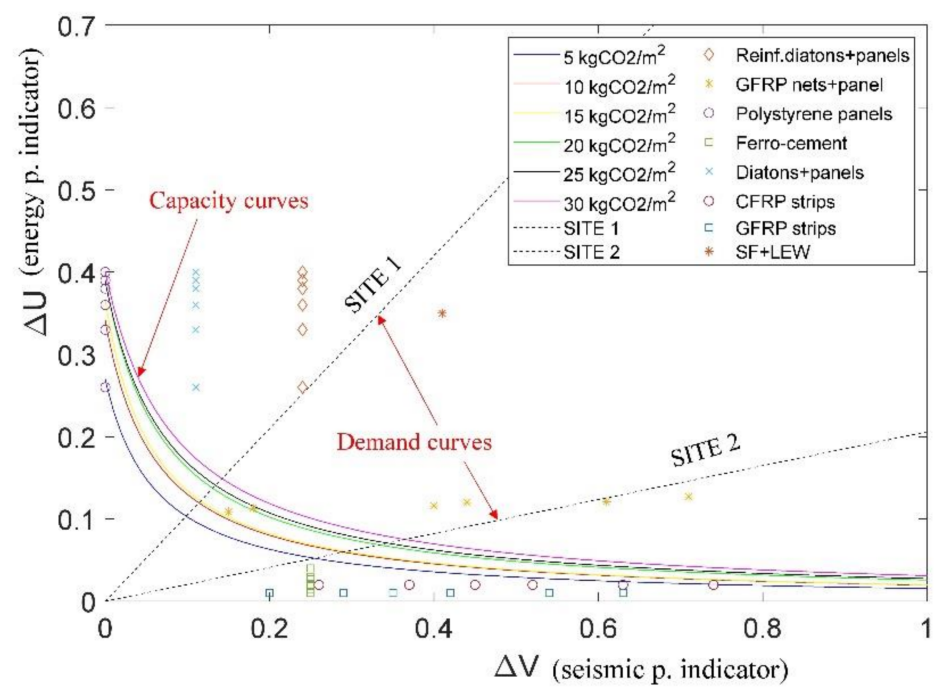

Figure 8. Comparison of the suggested methodology with literature models: use of demand curve (adapted from Figure 5 in [14]). 
All the considerations made in this paper emerge from the analysis of the installation phase of integrated interventions. Future studies will deal with the joint selection of integrated interventions, considering both global and local analysis of existing masonry buildings, as well as duly modifying the seismic performance indicators and their computation, with the extension of the proposed methodology to reinforced concrete buildings.

In addition, the promising results stimulate further investigations, also aiming to apply the proposed methodology to the other phases of the building life cycle, including maintenance and final disposal, in a similar way to that proposed in [14].

\section{Conclusions}

The paper illustrated a new methodology to assess the optimal integrated intervention in existing masonry buildings capable to limit out-of-plane (OOP) failure modes. Seismic and energy performance indicators were proposed to give a measure of the safety increment attained in terms of acceleration and thermal transmittance capacity. Absolute seismic and energy performance indicators were also suggested to correlate the capacity to the seismic and energetic demands.

The proposed methodology was applied to a case study in which the following integrated interventions were considered and studied: insulating panels (IP), steel tierods, and CFRP strips. Different economic budgets and environmental impacts were considered, corresponding to different increases of the seismic and energetic performances. The iso-cost curves were revealed to be a powerful tool in assessing the effects of varying acceleration demands on a given building to find the optimal integrated intervention or the economic/environmental impact foreseen with specific seismic and energy performance parameters.

The target economic budget and environmental impact were saturated, suitably modifying the thickness of IP, the diameter of tie-rods, and the number of CFRP strips. The energy performance indicators showed that small energy savings could lead to unsustainable environmental impacts, revealing the importance of the latter parameter in the assessment of eco-friendly and effective interventions in existing buildings.

It must be underlined that the main objective of the study was to demonstrate the feasibility of a multidisciplinary approach, allowing the assessment of the sustainability of integrated interventions in a coherent and unified way. Further developments are in progress in order to refine the method, also referring to relevant case studies, in order to identify typical values of the most relevant parameters, for example, in terms of cost and carbon footprint, in view of a full validation of the method.

Paralell research works are also devoted to extend the procedure to the whole operational life of the construction, supplementing the study with a sensitivity analysis aiming to assess how relevant management and use strategies may influence the life cycle cost analysis.

Author Contributions: Conceptualization, L.G., C.C. and P.C.; methodology, L.G.; software, C.C.; validation, L.G., C.C. and P.C.; formal analysis, L.G. and C.C.; investigation, L.G. and C.C.; data curation, L.G. and C.C.; writing-original draft preparation, L.G. and C.C.; writing-review and editing, L.G., C.C. and P.C.; project administration, P.C. and L.G.; funding acquisition, P.C. and L.G. All authors have read and agreed to the published version of the manuscript.

Funding: This research was funded by Italian Department of Civil Protection, Rete dei Laboratori Universitari di Ingegneria Sismica e Strutturale, project: ReLUIS-DPC 2019-2021-WP5 “Rapid, lowimpact and integrated retrofit interventions".

Data Availability Statement: Data is contained within the article.

Conflicts of Interest: The authors declare no conflict of interest. 


\section{References}

1. Shubbar, A.; Nasr, M.; Falah, M.; Al-Khafaji, Z. Towards net zero carbon economy: Improving the sustainability of existing industrial infrastructures in the UK. Energies 2021, 14, 5896. [CrossRef]

2. Balasbaneh, A.T.; Yeoh, D.; Juki, M.I.; Gohari, A.; Abidin, A.R.Z.; Bin Marsono, A.K. Applying three pillar indicator assessments on alternative floor systems: Life cycle study. Int. J. Life Cycle Assess. 2021, 26, 1-17. [CrossRef]

3. Trovato, M.R.; Nocera, F.; Giuffrida, S. Life-cycle assessment and monetary measurements for the carbon footprint reduction of public buildings. Sustainability 2020, 12, 3460. [CrossRef]

4. Scrucca, F.; Ingrao, C.; Maalouf, C.; Moussa, T.; Polidori, G.; Messineo, A.; Arcidiacono, C.; Asdrubali, F. Energy and carbon footprint assessment of production of hemp hurds for application in buildings. Environ. Impact Assess. Rev. 2020, 84, 106417. [CrossRef]

5. $\quad$ Bhutta, M.A.R.; Hussin, W.M.; Azreen, M.; Tahir, M.M. Sulphate resistance of geopolymer concrete prepared from blended waste fuel ash. J. Mater. Civ. Eng. 2014, 26, 4014080. [CrossRef]

6. Göswein, V.; Silvestre, J.D.; Lamb, S.; Gonçalves, A.B.; Pittau, F.; Freire, F.; Oosthuizen, D.; Lord, A.; Habert, G. Invasive alien plants as an alternative resource for concrete production-Multi-scale optimization including carbon compensation, cleared land and saved water runoff in South Africa. Resour. Conserv. Recycl. 2021, 167, 105361. [CrossRef]

7. Akbarnezhad, A.; Huan, M.; Mesgari, S.; Castel, A. Recycling of geopolymer concrete. Constr. Build. Mater. 2015, 101, 152-158. [CrossRef]

8. Sassu, M.; Giresini, L.; Bonannini, E.; Puppio, M.L. On the use of vibro-compressed units with bio-natural aggregate. Buildings 2016, 6, 40. [CrossRef]

9. Sassu, M.; Romanazzi, A.; Giresini, L.; Franco, W.; Ferraresi, C.; Quaglia, G.; Orefice, E. Production procedures and mechanical behaviour of interlocking stabilized compressed earth blocks (ISCEBs) manufactured using float ram 1.0 press. Eng. Solid Mech. 2018, 6, 89-104. [CrossRef]

10. Croce, P. New frontiers of composites applications in heritage buildings: Repair of exposed masonry of St. Nicola Church in Pisa. J. Compos. Sci. 2021, 5, 218. [CrossRef]

11. Vaccaro, P.A.; Galvín, A.P.; Ayuso, J.; Lozano-Lunar, A.; López-Uceda, A. Pollutant potential of reinforced concrete made with recycled plastic fibres from food packaging waste. Appl. Sci. 2021, 11, 8102. [CrossRef]

12. Sassu, M.; Stochino, F.; Mistretta, F. Assessment method for combined structural and energy retrofitting in masonry buildings. Buildings 2017, 7, 71. [CrossRef]

13. Giresini, L.; Paone, S.; Sassu, M. Integrated cost-analysis approach for seismic and thermal improvement of masonry building façades. Buildings 2020, 10, 143. [CrossRef]

14. Giresini, L.; Stochino, F.; Sassu, M. Economic vs environmental isocost and isoperformance curves for the seismic and energy improvement of buildings considering Life Cycle Assessment. Eng. Struct. 2021, 233, 111923. [CrossRef]

15. Menna, C.; Del Vecchio, C.; Di Ludovico, M.; Mauro, G.M.; Ascione, F.; Prota, A. Conceptual design of integrated seismic and energy retrofit interventions. J. Build. Eng. 2021, 38, 102190. [CrossRef]

16. Croce, P.; Formichi, P.; Landi, F. Influence of reinforcing steel corrosion on life cycle reliability assessment of existing r.c. buildings. Buildings 2020, 10, 99. [CrossRef]

17. Croce, P.; Formichi, P.; Landi, F.; Marsili, F. Climate change: Impact on snow loads on structures. Cold Reg. Sci. Technol. 2018, 150, 35-50. [CrossRef]

18. Croce, P.; Formichi, P.; Landi, F. Climate change: Impacts on climatic actions and structural reliability. Appl. Sci. 2019, 9, 5416. [CrossRef]

19. Croce, P.; Formichi, P.; Landi, F.; Mercogliano, P.; Bucchignani, E.; Dosio, A.; Dimova, S. The snow load in Europe and the climate change. Clim. Risk Manag. 2018, 20, 138-154. [CrossRef]

20. Beconcini, M.L.; Croce, P.; Marsili, F.; Muzzi, M.; Rosso, E. Probabilistic reliability assessment of a heritage structure under horizontal loads. Probabilistic Eng. Mech. 2016, 45, 198-211. [CrossRef]

21. Croce, P.; Beconcini, M.L.; Formichi, P.; Cioni, P.; Landi, F.; Mochi, C.; Giuri, R. Influence of mechanical parameters on non-linear static analysis of masonry buildings: A relevant case-study. Procedia Struct. Integr. 2018, 11, 331-338. [CrossRef]

22. Beconcini, M.L.; Cioni, P.; Croce, P.; Formichi, P.; Landi, F.; Mochi, C. Non-linear static analysis of masonry buildings under seismic actions. International Institute of Informatics and Systemics. In Proceedings of the 22th World Multi-Conference on Systemics, Cybernetics and Informatics, Orlando, FL, USA, 8-11 July 2018; pp. 126-131, IMSCI 2018. ISBN 9781941763841. Available online: http:/ / www.iiisci.org/Journal/CV\$/sci/pdfs/EA239AY18.pdf (accessed on 15 September 2021).

23. Lagomarsino, S.; Cattari, S. PERPETUATE guidelines for seismic performance-based assessment of cultural heritage masonry structures. Bull. Earthq. Eng. 2015, 13, 13-47. [CrossRef]

24. Casapulla, C.; Argiento, L.U. The comparative role of friction in local out-of-plane mechanisms of masonry buildings. Pushover analysis and experimental investigation. Eng. Struct. 2016, 126, 158-173. [CrossRef]

25. Casapulla, C. Local out-of-plane failure modes in traditional block-masonry buildings. In Masonry Construction in Active Seismic Regions; Rupakhety, R., Gautam, D., Eds.; Elsevier: Amsterdam, The Netherlands, 2021; pp. 289-322, ISBN 9780128210871. [CrossRef]

26. Casapulla, C.; Giresini, L.; Argiento, L.U.; Maione, A. Nonlinear static and dynamic analysis of rocking masonry corners using rigid macro-block modeling. Int. J. Struct. Stab. Dyn. 2019, 19, 1950137. [CrossRef] 
27. Giresini, L. Design strategy for the rocking stability of horizontally restrained masonry walls. In Proceedings of the COMPDYN 2017 6th ECCOMAS Thematic Conference on Computational Methods in Structural Dynamics and Earthquake Engineering, Rhodes Island, Greece, 15-17 June 2017; Papadrakakis, M.F.M., Ed.; Volume 2, pp. 2963-2979. [CrossRef]

28. Solarino, F.; Giresini, L. Fragility curves and seismic demand hazard analysis of rocking walls restrained with elasto-plastic ties. Earthq. Eng. Struct. Dyn. 2021, 50, 3602-3622. [CrossRef]

29. Casapulla, C.; Argiento, L.U.; Maione, A.; Speranza, E. Upgraded formulations for the onset of local mechanisms in multi-storey masonry buildings using limit analysis. Structures 2021, 31, 380-394. [CrossRef]

30. Solarino, F.; Oliveira, D.; Giresini, L. Wall-to-horizontal diaphragm connections in historical buildings: A state-of-the-art review. Eng. Struct. 2019, 199, 109559. [CrossRef]

31. De Falco, A.; Giresini, L.; Sassu, M. Temporary preventive seismic reinforcements on historic churches: Numerical modeling of San Frediano in Pisa. Appl. Mech. Mater. 2013, 351-352, 1393-1396. [CrossRef]

32. Giresini, L.; Puppio, M.L.; Taddei, F. Experimental pull-out tests and design indications for strength anchors installed in masonry walls. Mater. Struct. 2020, 53, 103. [CrossRef]

33. Maione, A.; Casapulla, C.; Di Ludovico, M.; Prota, A.; Ceroni, F. Efficiency of injected anchors in connecting T-shaped masonry walls: A modelling approach. Constr. Build. Mater. 2021, 301, 124051. [CrossRef]

34. Giresini, L.; Solarino, F.; Taddei, F.; Mueller, G. Experimental estimation of energy dissipation in rocking masonry walls restrained by an innovative seismic dissipator (LICORD). Bull. Earthq. Eng. 2021, 19, 2265-2289. [CrossRef]

35. Giresini, L.; Taddei, F.; Solarino, F.; Mueller, G.; Croce, P. Influence of stiffness and damping parameters of passive seismic control devices in one-sided rocking of masonry walls. J. Struct. Eng. (ASCE) 2021, 19, 2265-2289. [CrossRef]

36. Croce, P.; Landi, F.; Formichi, P. Probabilistic seismic assessment of existing masonry buildings. Buildings 2019, 9, 237. [CrossRef]

37. $\mathrm{Hu}, \mathrm{M} . \mathrm{A}$. Building life-cycle embodied performance index-The relationship between embodied energy, embodied carbon and environmental impact. Energies 2020, 13, 1905. [CrossRef]

38. De Wolf, C.; Pomponi, F.; Moncaster, A. Measuring embodied carbon dioxide equivalent of buildings: A review and critique of current industry practice. Energy Build. 2017, 140, 68-80. [CrossRef]

39. Cabeza, L.F.; Boquera, L.; Chàfer, M.; Vérez, D. Embodied energy and embodied carbon of structural building materials: Worldwide progress and barriers through literature map analysis. Energy Build. 2021, 231, 110612. [CrossRef]

40. Brambilla, A.; Salvalai, G.; Imperadori, M.; Sesana, M.M. Nearly zero energy building renovation: From energy efficiency to environmental efficiency, a pilot case study. Energy Build. 2018, 166, 271-283. [CrossRef]

41. Wei, H.H.; Shohet, I.M.; Skibniewski, M.J.; Shapira, S.; Yao, X. Assessing the lifecycle sustainability costs and benefits of seismic mitigation designs for buildings. J. Arch. Eng. 2016, 22, 04015011. [CrossRef]

42. Caliò, I.; Marletta, M.; Pantò, B. A new discrete element model for the evaluation of the seismic behaviour of unreinforced masonry buildings. Eng. Struct. 2012, 40, 327-338. [CrossRef]

43. Alecci, V.; De Stefano, M.; Focacci, F.; Luciano, R.; Rovero, L.; Stipo, G. Strengthening masonry arches with lime-based mortar composite. Buildings 2017, 7, 49. [CrossRef]

44. Beconcini, M.; Croce, P.; Formichi, P.; Landi, F.; Puccini, B. Experimental evaluation of shear behavior of stone masonry wall. Materials 2021, 14, 2313. [CrossRef]

45. Ministero delle Infrastrutture e dei Trasporti. Istruzioni per l'Applicazione dell' Aggiornamento delle 'Norme Tecniche per le Costruzioni' di cui al Decreto Ministeriale 17 Gennaio 2018; Circolare 21 gennaio 2019, n. 7 C.S.LL.PP.; Poligrafico dello Stato: Rome, Italy, 2019. (In Italian)

46. Ministero delle Infrastrutture e dei Trasporti. Norme Tecniche per le Costruzioni"; Poligrafico dello Stato: Rome, Italy, 2018. (In Italian)

47. Heyman, J. The stone skeleton. Int. J. Solids Struct. 1966, 2, 249-279. [CrossRef]

48. EN ISO 6946:2017. Building Components and Building Elements-Thermal Resistance and Thermal Transmittance-Calculation Methods; CEN: Brussels, Belgium, 2017.

49. EN ISO 10077 1:2017. Thermal Performance of Windows, Doors and Shutters-Calculation of Thermal Transmittance; CEN: Brussels, Belgium, 2017.

50. EN ISO 10211:2017. Thermal Bridges in Building Construction-Heat Flows and Surface Temperatures-Detailed Calculations; CEN: Brussels, Belgium, 2017.

51. EN 15804:2012+A2. Sustainability of Construction Works—Environmental Product Declarations—Core Rules for the Product Category of Construction Products; CEN: Brussels, Belgium, 2019.

52. Caliò, I.; Occhipinti, G.; (University of Catania, Catania, Italy). Personal communication, 2021.

53. National Research Council. CNR-DT 200 R1/2013: Guide for the Design and Construction of Externally Bonded FRP Systems for Strengthening Existing Structures; CNR-Advisory Committee on Technical Recommendations for Construction: Rome, Italy, 2013.

54. Bulletin of unitary costs in Tuscany Region (Prezzario Lavori Pubblici Regione Toscana). Available online: http://prezzariollpp. regione.toscana.it/\#2021 (accessed on 15 September 2021).

55. One Click LCA —Computer Program; One Click LCA Ltd.: Helsinki, Finland, 2021.

56. Stoiber, N.; Hammerl, M.; Kromoser, B. Cradle-to-gate life cycle assessment of CFRP reinforcement for concrete structures: Calculation basis and exemplary application. J. Clean. Prod. 2021, 280, 124300. [CrossRef]

57. Specific Modulus. Available online: https://en.wikipedia.org/wiki/Specific_modulus (accessed on 6 October 2021). 
58. Sassoni, E.; Sarti, V.; Bellini, A.; Mazzotti, C.; Franzoni, E. The role of mortar joints in FRP debonding from masonry. Compos. Part B Eng. 2018, 135, 166-174. [CrossRef]

59. Ceroni, F.; Ferracuti, B.; Pecce, M.; Savoia, M. Assessment of a bond strength model for FRP reinforcement externally bonded over masonry blocks. Compos. Part B Eng. 2014, 61, 147-161. [CrossRef]

60. Gnip, I.; Vejelis, S.; Vaitkus, S. Thermal conductivity of expanded polystyrene (EPS) at $10^{\circ} \mathrm{C}$ and its conversion to temperatures within interval from 0 to $50{ }^{\circ} \mathrm{C}$. Energy Build. 2012, 52, 107-111. [CrossRef]

61. Ministero dello Sviluppo Economico. Requisiti Specifici per Gli Edifici Esistenti Soggetti a Riqualificazione Energetica一Appendice B; Poligrafico dello Stato: Rome, Italy, 2015. (In Italian)

62. Eur/Dollar Change. Available online: https://www.ecb.europa.eu/stats/policy_and_exchange_rates/euro_reference_exchange_ rates/html/eurofxref-graph-usd.en.html (accessed on 6 October 2021).

63. Mistretta, F.; Stochino, F.; Sassu, M. Structural and thermal retrofitting of masonry walls: An integrated cost-analysis approach for the Italian context. Build. Environ. 2019, 155, 127-136. [CrossRef]

64. Giresini, L.; Butenweg, C. Earthquake resistant design of structures according to Eurocode 8. In Structural Dynamics with Applications in Earthquake and Wind Engineering; Springer: Berlin/Heidelberg, Germany, 2019; pp. 197-358. 